\title{
Determination of vulnerable regions of SARS-CoV-2 in Malaysia using meteorology and air quality data
}

\author{
Prasanna Mohan Viswanathan ${ }^{1}$ (D) . Chidambaram Sabarathinam ${ }^{2}$ (D) \\ Shankar Karuppannan ${ }^{3}$ (D) . Gnanachandrasamy Gopalakrishnan ${ }^{4,5}$ (i)
}

Received: 3 July 2020 / Accepted: 30 July 2021 / Published online: 10 August 2021

(C) The Author(s), under exclusive licence to Springer Nature B.V. 2021

\begin{abstract}
This study aims to explore the state-wise assessment of SARS-CoV-2 (COVID-19) pandemic spread in Malaysia with focus on influence of meteorological parameters and air quality. In this study, state-wise COVID-19 data, meteorological parameters and air quality index (AQI) were collected from March 13 to April 30, 2020, which encompass three movement control order (MCO) periods in the country. Overall, total infected cases were observed to be higher in MCO phase 1 and 2 and significantly reduced in MCO phase 3. Due to the variation in the spatial interval of population density and individual immunity, the relationship of these parameters to pandemic spread could not be achieved. The study infers that temperature (T) between 23 and $25{ }^{\circ} \mathrm{C}$ and relative humidity (RH) (70-80\%) triggered the pandemic spread by increase in the infected cases in northern and central Peninsular Malaysia. Selangor, WP Kuala Lumpur and WP Putrajaya show significantly high infected cases and a definite trend was not observed with respect to a particular meteorological factor. It is identified that high precipitation (PPT), RH and good air quality have reduced the spread in East Malaysia. A negative correlation of T and AQI and positive correlation of RH with total infected cases were found during MCO phase 3. Principal component analysis (PCA) indicated that T, RH, PPT, dew point (DP) and AQI are the main controlling factors for the spread across the country apart from social distancing. Vulnerability zones were identified based on the spatial analysis of T, RH, PPT and AQI with reference to total infected cases. Based on time series analysis, it was determined that higher RH and T in Peninsular Malaysia and high amount of PPT, RH and good air quality in East Malaysia have controlled the spreading during MCO phase 3. The predominance of D614 mutant was observed prior to March and decreases at the end of March, coinciding with the fluctuation of meteorological factors and air quality. The outcome of this study gives a general awareness to the public on COVID-19 and the influence of meteorological factors. It will also help the policymakers to enhance the management plans against the pandemic spreading apart from social distancing in the next wave of COVID-19.
\end{abstract}

Keywords COVID-19 · Temperature · Relative humidity $\cdot$ Air quality $\cdot$ D614 mutant · Vulnerability

Prasanna Mohan Viswanathan geoprasanna@gmail.com

Extended author information available on the last page of the article 


\section{Introduction}

The novel coronavirus disease (COVID-19) was first reported in Wuhan City, China, in December 2019 (Lu et al., 2020; Xu et al., 2020a, 2020b). Later, the virus rapidly spread and became a worldwide health issue leading to the health havoc in many countries (Asyary $\&$ Veruswati, 2020; Singhal, 2020). The impact of the virus was more in the developing countries than developed countries (Hopman et al., 2020). Analytical results of the fresh strain of the CoV-2 contain genome 50-80\% sequence similar to the MERS (Middle East respiratory syndrome) and SARS (severe acute respiratory syndrome) (Paital et al., 2020). Symptoms of the infected (SARS-CoV-2) patients' initiate with dry cough, tiredness, sore throat and fever (Huang et al., 2020; Sohrabi et al., 2020). But few, including acute respiratory distress syndrome (ARDS), may have severe and even fatal complications (Chen et al., 2020). Based on the personal immunity, it can grow in the respiratory organs and tissues ultimately affecting the health (Shi et al., 2020). The aged patients and those with premorbid health issues are likely to be more vulnerable to COVID-19 (Morley \& Vellas, 2020; Garnier-Crussard et al., 2020).

Researchers are more interested to focus and understand the relationship of COVID-19 with various environments from atmosphere to biosphere. Recent epidemiological studies examined the effect of changes in climate and meteorological variables on an important newly described infection, namely the severe acute syndrome (SARS), exemplify the continuation of scientific interest in the matter (Zhou \& Jiang, 2004). In addition, there are epidemiological and pathophysiological evidence suggesting an impact of emission levels on the upper and lower respiratory system in conjunction with various meteorological factors such as temperature, humidity, rainfall and atmospheric pressure (Braat et al., 2002; Muhling et al., 1984; Watson et al., 2006). Numerous studies have highlighted the relationship between meteorological parameters relating air quality and COVID-19 spread globally (Tosepu et al., 2020; Kumar, 2020; Ma et al., 2020; Guo et al., 2021; Jain et al., 2021; Shankar et al., 2021). Furthermore, meteorological variables have also been related to other diseases including cardiovascular diseases and respiratory diseases have also been reported (Bartzokas et al., 2004).

Xie and Zhu (2020) studied the ambient temperature relation with COVID-19 diseases in China and reported that mean temperature has a good linear relationship with number of cases and the spread varied with respect to temperature and humidity in Wuhan (Ma et al., 2020). Few researchers (Biktasheva, 2020; Wang et al., 2020) studied the COVID-19 mortality and the study reveals that death ranges between $0.75 \%$ and $3 \%$ in Wuhan. Daily death cases were positively associated with temperature $(r=0.44)$ and negatively with humidity $(r=-0.32)$. Few studies reported that the COVID-19 spread was related to the environmental parameters (Tosepu et al., 2020; Wang et al., 2020). Mario Coccia (2020) studied the transmission dynamics by air-pollution to human and man to man transmission. Researchers have attempted to unravel the relationship of COVID-19 spread to population density, number of infected cases and climate factors like, average humidity, precipitation, radiation, wind speed and temperature (Şahin, 2020; Mohsen et al., 2020). The result indicates that density of population and intra-provincial movement have a direct connection to the outbreak of the infection. In Australia, the COVID-19 RNA was identified from catchment area with wastewater using RT-qPCR assay and later by Monte Carlo simulation model projected a mean value of infections varies between 171 and 1090. The projected simulation was found to match with experimental observations (Ahmed et al., 2020). Air quality parameters like $\mathrm{NO}_{2}, \mathrm{SO}_{2}$ and $\mathrm{PM}_{10}$ monitored before and after lockdown period 
of COVID-19 report a decrease in levels of pollution as most industries were closed and movement of vehicles was controlled globally (Otmani et al., 2020).

Malaysia is one among the developing countries with reported COVID-19 cases to be 8515 as on June 17, 2020, considered as one of the highest infected cases in Southeast Asia. Few MCOs were declared during March and April 2020 with strict standard operating procedures (SOPs) set by the country including wearing mask and social distancing. Only few studies (Abdullah et al., 2020; Azlan et al., 2020; See et al., 2020; Che Mat et al., 2020) are reported on the COVID-19 in Malaysia, and they discussed only the daily cases, knowledge, practices and attitude of the people to COVID-19. There exist research gaps to unravel the meteorological influence on COVID-19 spreading in the country. Hence, an attempt was made to determine the significance of meteorological parameters (T, RH, PPT, DP and wind speed (WS)) and AQI to the COVID-19 spread in different states of Malaysia. This study also focuses to determine the effect of movement controlling order (MCO) periods to the pandemic spread and the CoV-2 gene mutation with respect to meteorological variables. Spatial analysis and time series analysis in GIS environment were used to identify the key regions, which are vulnerable to spread during different MCO phases.

\section{Study area}

The country of Malaysia is the current research area, which is closer to the equator, located between $2^{\circ} 30^{\prime} \mathrm{N}$ and $112^{\circ} 30^{\prime} \mathrm{E}$ with an area spread of $329960.22 \mathrm{~km}^{2}$. It having a coast line length of about $4800 \mathrm{~km}$ (Abdullah, 1993). Malaysia consists of two large landmasses, Peninsular Malaysia (West Malaysia) and the Sabah-Sarawak (East Malaysia) in northern Borneo territories (Ismail et al., 2017). Borneo's large island is shared with Brunei, whereas Indonesia and Philippines border to the north. West Malaysia covers major part of the Malay Peninsula (14 states) and East Malaysia has two large states namely Sabah and Sarawak. In general, many areas in West Malaysia (Peninsular) are considered as developed with more urban and industrial regions compared to East Malaysia with tropical weather. The current population of Malaysia is 32,749,668 as of June 6, 2021, based on worldometer database. The population density in Malaysia is $99 / \mathrm{Km}^{2}$ and $78 \%$ of the population are in urban areas. The average temperatures vary from 25 to $35^{\circ} \mathrm{C}$. The southwest monsoon begins from May to September, and the northeast monsoon from November to March. The pleasant weather in West Malaysia is observed for the period between January and February, and during April in East Malaysia (specifically in Sabah), and June to July in Sarawak. The yearly average rainfall in West Malaysia is $2500 \mathrm{~mm}$ and the East Malaysia is $5080 \mathrm{~mm}$. Major economy comes from petroleum and natural gas; they are mainly spotted in the offshore of the northeast side of Sarawak, along the west coast of Sabah and east coast of the peninsula.

\section{Methodology}

Data of total cases, new cases, total deaths and total recovered cases for the entire country (Malaysia) were collected from 1 March to 30 April. Total cases (TC), daily new cases (DNC) and population density data were collected for 16 states (Selangor, Sabah, Johor, Sarawak, Perak, Kedah, Kelantan, WP Kuala Lumpur, Pinang, Pahang, Terengganu, N Sembilan, Malacca (Melaka), Perlis, WP Labuan and WP Putrajaya) during 13 March to 30 April, which 
covers three important movement control order (MCO) periods. The above data were collected from Department of Statistics Malaysia website (www.dosm.gov.my). After the first case was recorded on January 25, 2020, the country has announced five phases of movement control order (MCO) on March 18, April 1, April 14, April 29 and May 12, 2020.

The meteorological parameters such as temperature (T), relative humidity $(\mathrm{RH})$, precipitation (PPT), dew point (DP), wind speed (WS) were collected from NASA website (https:// power.larc.nasa.gov). Air quality index (AQI) data were collected from Air Quality Historical Data Platform website (https://aqicn.org/data-platform), sourced from Malaysia Department of Environment (DOE) and Air Pollutant Index Management System. These data are not fully verified or validated. AQI is used for defining and classifying Malaysia's ambient air quality based on potential public health implications (DOE, 1997). It is a non-dimensional number that is calculated according to the average urban daily pollutant concentration (Dominick et al., 2012; DOE, 2012). AQI consists of five basic pollutants such as $\mathrm{O}_{3}, \mathrm{CO}, \mathrm{SO}_{2}, \mathrm{NO}_{2}$ and $\mathrm{PM}_{10}$. Data source for mutation study was acquired at www.cov.lanl.gov based on contemporary data from GISAID.

Correlation and factor analysis were carried out for COVID-19 data, meteorological parameters and AQI for three MCO phases using statistical software, Statistical Package for Social Studies (SPSS) version 17. Pearson correlation was adopted for the data collected at each state. Principal component analysis was also performed for the collected data to determine the factors influencing the COVID-19 spread and mortality. Varimax rotation and Kaiser normalization were used to extract Eigen values greater than one (Prasanna et al., 2010).

The Geographic Information System (GIS) with the Spatial Statistical Analyst Package and the Inverse Distance Weighted (IDW) method is a powerful package for the assessment and regular monitoring of the COVID-19 pandemic (Childs, 2004; Bagyaraj et al., 2020). The IDW interpolation method was used to prepare spatial variation maps and vulnerable risk maps. The IDW model is classified, and its ranking has been used to evaluate the appropriate risk zone affected. In this study, the distribution of total cases versus PPT, T, RH and AQI maps was classified into three classes as vulnerable, moderately vulnerable and non-vulnerable. Thematic maps were prepared using IDW methods that have been converted to the raster format for reclassification. Preparation and reclassification of thematic maps were based on the influence of each factor, their effect on the meteorological parameters and on COVID19 cases. After reclassification, the maps were ranked according to their level of importance and class value. This ranking weighting is also given to each meteorological parameter layer. The risk zone analysis map was created by overlaying all the thematic maps together using the weighted overlay method in ArcGIS software version 10.4 under the Spatial Analyst tool (Cengiz and Akbulak, 2009; Peter et al., 2011, Senthil Kumar \& Shankar, 2014). The final integrated output of the COVID-19 vulnerable zone map has been categorized into three zones. MCO time series maps were prepared using bar charts for meteorological parameters. Normalization of meteorological parameters was done in time series analysis for better visualization of data in the maps.

\section{Results}

\subsection{COVID-19 scenario in Malaysia}

Significant number of infected cases were recorded in the first three MCO phases (18-31 March, 1-13 April and 14-9 April, 2020). So, the current study is focusing on these three 
important periods for further discussion. Figure 1 explains the COVID-19 trends for total cases, daily new cases, total deaths and total recovered records in the country from March 1 to April 30, 2020. Overall, it was observed that, MCO phase 3 reflected a significant reduction in the number of daily new cases due to effective SOPs. No major variation in total cases, total deaths and total recovered were observed. Hence, MCO phase 3 period is more effective than the other phases reflecting the decrease in pandemic spread in the country.

\subsection{Infected cases by state-wise in Malaysia}

A total of 16 states were considered for this study, which covers the whole country including West and East Malaysia. Total infected cases (TC) and daily new cases (DNC) were considered for the following discussion. Through Supplementary Fig. 1, variations in number of infected cases at different states were clearly observed in three MCO periods. Overall, an increasing trend of total infected cases was observed in MCO phase 1 and 2 and subsequently stable in phase 3 . The daily new cases reflected a decreasing trend from phase 1 to 3 , except in few states.

\subsection{Impact of meteorological factors to COVID-19 cases}

Meteorological parameters affect the respiratory system by decreasing the human body's local resistance to infection and by affecting the body's general resistance by influencing infection spread (Tromp, 1980; Tromp \& Hoffman, 1964). Different meteorological factors influence the respiratory tract to varying degrees but the air temperature and humidity have the most important effect (Silva et al., 2014). The influence of meteorological parameters

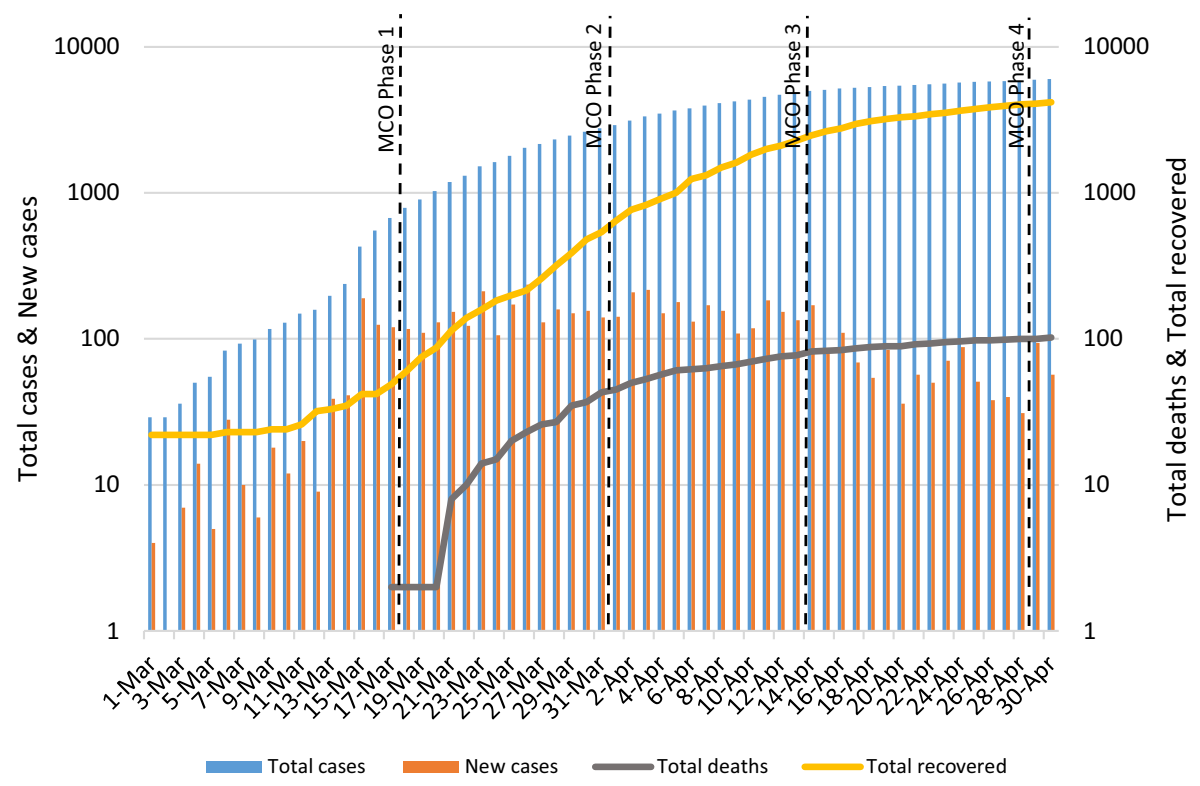

Fig. 1 Trend of various COVID-19 cases in Malaysia 
(T, RH, DP, PPT and WS) and AQI to the infected cases during MCO periods at different states is shown in Supplementary Fig. 2. Overall, it reflects that T, RH and PPT are the main controlling factors for the pandemic spread across all the states in the country. Low AQI values indicating good air quality has suppressed the spread in MCO phase 3.

\section{Discussion}

\subsection{Infected cases in MCO periods}

Each state has different trends of infected cases during the three phases of MCO (Fig. 2). The higher number of DNC was recorded in MCO phase 1 (2123), followed by phase 2 (2064) and phase 3 (970) (Department of Statistics, Malaysia). The difference between phase 1 and phase 2 was 59 DNC only indicates that MCO phase 1 was not effective and thus resulted in more DNC in MCO phase 2. But the difference between phase 2 and 3 was 1094, which indicates the MCO phase 2 was much more effective and drastically drop in DNC during phase 3. WP Kuala Lumpur and Selangor had a high record of DNC in the country. Sabah, Johor, Perak, Kedah, Kelantan and Pinang shows the decreasing trend of total daily new cases from phase 1 to 3 , where the effectiveness of these movement controls had significantly reduced the infected cases. In other hand, Selangor, WP Kuala Lumpur, Sarawak, Pahang, N Sembilan, Melaka and WP Putrajaya do not show any significant changes in the DNC in three MCO phases.

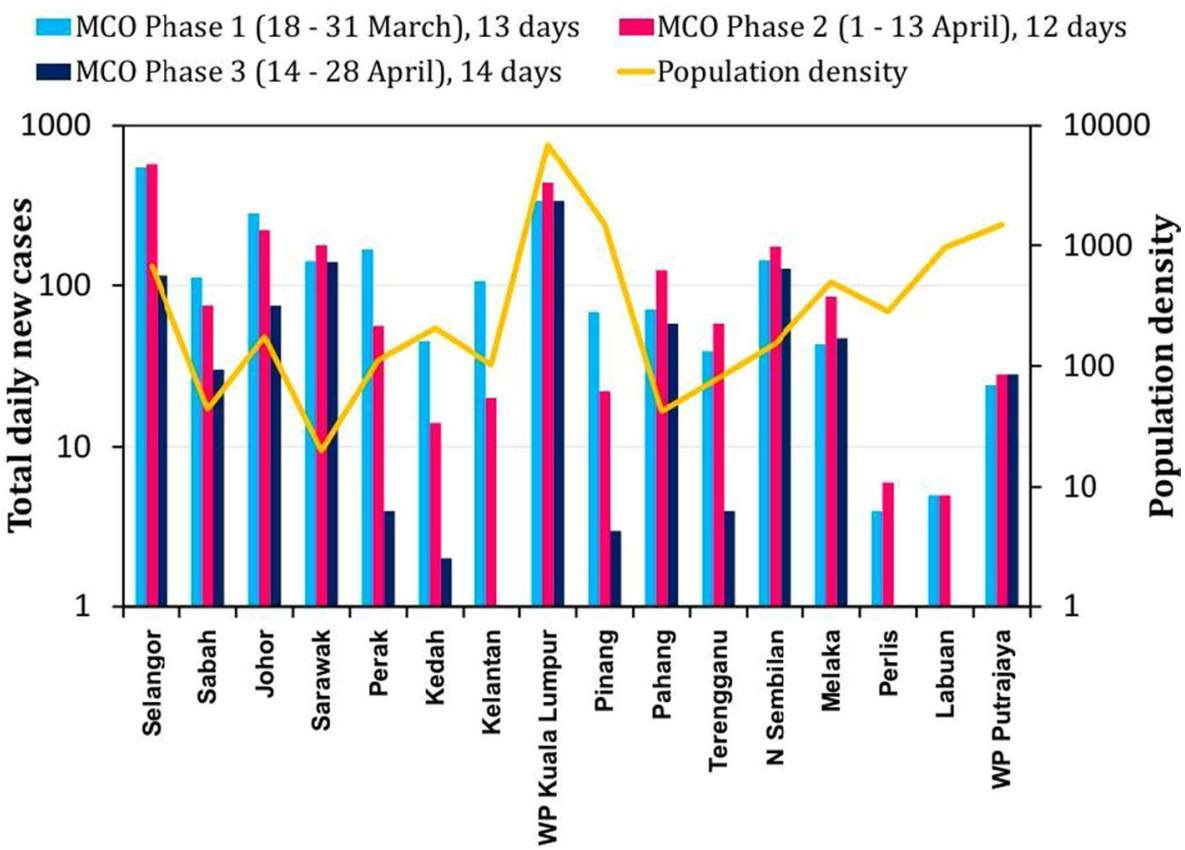

Fig. 2 Total daily new cases in three MCO periods 
An attempt was also being made to know the influence of population density to the pandemic spread. In many studies, a number of scaling mechanisms were explored in dynamic epidemic models to characterize the relationship between transmission rate and population (Anderson \& May, 1991; de Jong et al., 1995; Mc Callum et al., 2001; Begon et al., 2002; Rhodes \& Anderson, 2008; Ferrari et al., 2011). Among the states considered for this study, highest population density was recorded in WP Kuala Lumpur, followed by Pinang, WP Putrajaya, Selangor, Melaka, Perlis, Kedah and Johor in Peninsular Malaysia, whereas lowest in East Malaysia (Sabah and Sarawak). A positive correlation between increased infected cases and high population in major cities of Peninsular Malaysia indicate that population density is also a factor for pandemic spread. In high-density groups, like crowds at mass events, the spontaneous movement and individual interaction initially raise contact frequency (Hu et al., 2013). But, a negative relationship was observed (increased infected cases with low population density) in East Malaysia. Hence, the impact of population density to the pandemic spread in the country is still been inconclusive due to the variation in the spatial interval of population and the immunity of the population.

\subsection{Temperature}

The average $T$ of different states shows three distinct cluster, cluster 1 represents of Sarawak, Perak, Sabah, Pinang, Terengganu, Kelantan, Kedah, WP Putrajaya, Perlis and Labuan with $\mathrm{T}$ ranging from 23 to $25^{\circ} \mathrm{C}$. These states show an increase in pandemic spread with T (Fig. 3). The cluster 2 consisting of Johor, N Sembilan, Pahang and Melaka has $\mathrm{T}$ ranging from 27 to $29{ }^{\circ} \mathrm{C}$ with increasing trend of spread. It is interesting to note that the cluster 3 of Selangor and WP Kuala Lumpur show comparatively higher spreading in the country with the T ranging from 27 to $28{ }^{\circ} \mathrm{C}$. Overall, it shows that most of the states with optimal temperature $\left(23-25^{\circ} \mathrm{C}\right)$ has resulted in the increase in spread. Similar observation was made in Shenmu, China, where the T falls between $20{ }^{\circ} \mathrm{C}$ and $25{ }^{\circ} \mathrm{C}$. This temperature range was inferred to support the infection to spread during winter (Liu et al., 2016). Some other countries, such as Israel, Guinea, Hawaii and Chile, reported that mortality from respiratory diseases increased with decreasing T, comparable to our findings (Reese \& Marchette, 1991; Hierholzer et al., 1994; Lieberman \& Friger, 1999; Chan et al., 2002; Avendano et al., 2003; Falagas et al., 2008; Fallah \& Mayvaneh, 2016), and was strongly associated with low T (Dadbakhsh et al., 2017; Gómez-Acebo et al., 2013; Macfarlane, 1977). An analysis of cold exposure and immune function found that lower T could suppress immune function (Shephard \& Shek, 1998). So, the influence of COVID-19 spread with the range of $\mathrm{T}\left(23-25^{\circ} \mathrm{C}\right)$ recorded high number of spreading apart from the other controlling factors such as population density, social distancing and immune system of people.

\subsection{Relative humidity}

Humidity is also an important meteorological factor to control the respiratory tract infections (Liu et al., 2016). Low humidity triggers the removal of water vapor from the body cells, resulting in the drying and cracking of nasal mucosa and also relaxing ciliary movements in the respiratory tract, thus increasing susceptibility to infection (Tromp \& Hoffman, 1964).

The average $\mathrm{RH}$ in most of the states show negative association with spreading rates, which indicate the increase in infected cases in low humidity condition. Previous studies 


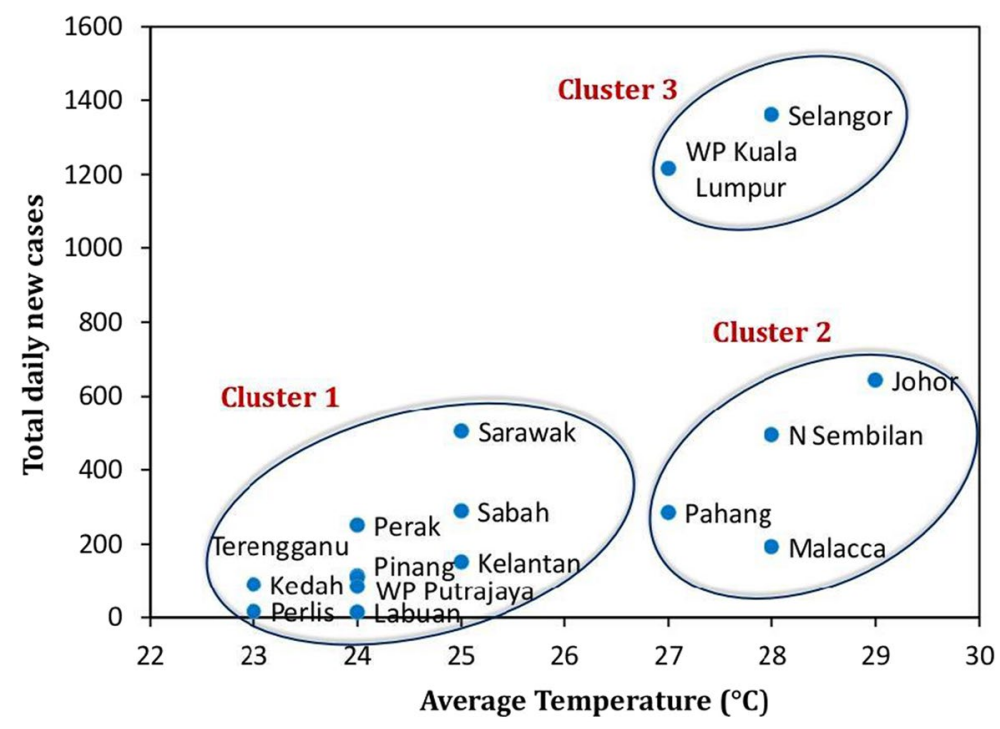

Fig. 3 Average temperature vs. total daily new cases

have found that higher RH levels decrease the survival of lipid enveloped viruses such as influenza A, influenza B, RSV and PIV (Schaffer et al., 1976; Tang, 2009; Tellier, 2009). The high number of spreading was clearly observed between 76 and $87 \%$ RH (Fig. 4). The stability of aerosolized influenza virus is moderate at high RH (60-80\%) (Schaffer et al., 1976), which almost coincides with our results. Humidity is an important mortality factor, the low humidity could cause a considerable increase in mortality rates, possibly due to influenza-related mechanisms (Barreca, 2012; Barreca \& Shimshack, 2012). In this study, it was observed that the decreasing of COVID-19 spreading associated with increasing RH. The droplet nuclei in the air are essential for virus transmission, when exhaled respiratory droplets settle at high humidity very quickly so that it is difficult to spread the virus (Lowen et al., 2007). Pandemic virus transmission is efficient under cold, dry conditions (Steel et al., 2011), and viruses have a higher survival rate in line with decreases in absolute humidity (Shaman et al., 2009). It is also interesting to observe that Sabah and Sarawak fall at same high RH (93\%) with different spreading rates, which indicate that these two States are located in totally different geographic locations and climate conditions (East Malaysia). Surprisingly, Selangor and WP Kuala Lumpur show as a distinct zone with high spreading rate at higher humid conditions, which indicate other factors are also influencing the spread in this region.

\subsection{Precipitation}

Rainfall is recognized as one of the main natural processes for improving air quality by removing the atmospheric pollutants, particularly particulate matter, that carry the viruses in the air (Duhanyan \& Roustan, 2011; Guo et al., 2016; Ouyang et al., 2015). The collected precipitation data between March and April 2020 fall in the transition period between NE monsoon and SW monsoon. Average PPT shows three different trends with the total daily 


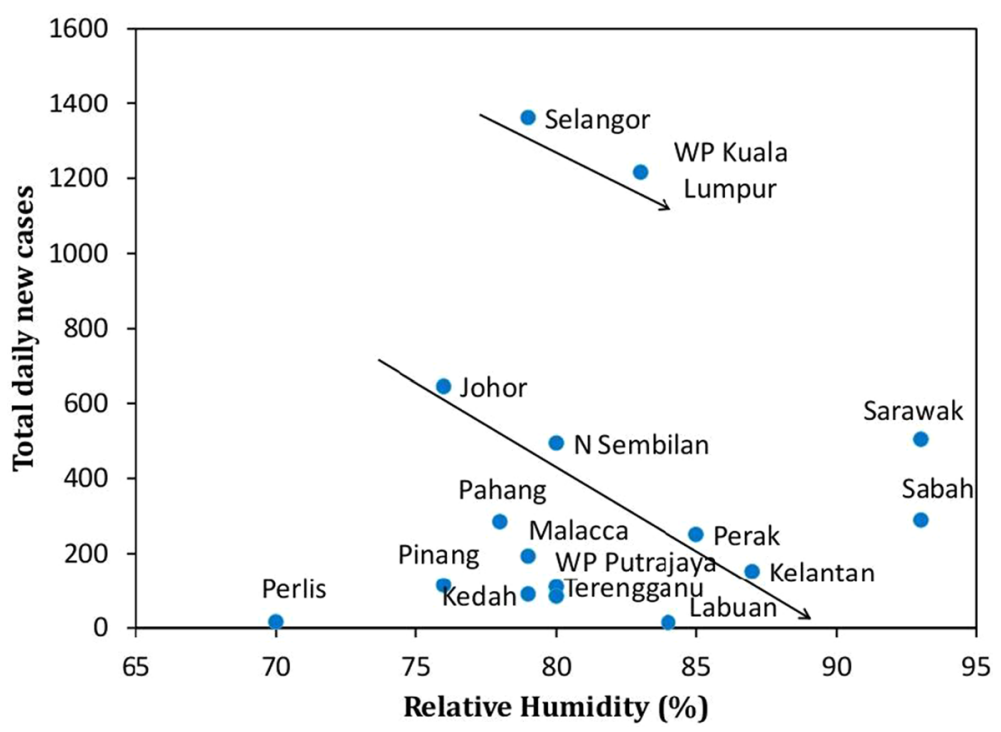

Fig. 4 Average relative humidity vs. total daily new cases

new cases (Fig. 5). Cluster 1 consists of most of the states with negative influence on the transmissivity of COVID-19, where the spreading rates decreased with high PPT. It indicates that high rainfall can wash out the droplet nuclei in air and reduced the transmission of virus (Comrie, 2007; Lowen et al., 2007). Similar observation made by Masoumi et al. (2017) found that the concentration of the pollutants $\left(\mathrm{PM}_{10}, \mathrm{NO}\right.$ and $\left.\mathrm{NO}_{2}\right)$ during epidemic periods was significantly lower during the rainfall compared to the non-epidemic period. A stronger washout impact with a rainfall threshold of $7 \mathrm{~mm}$ was observed for $\mathrm{PM}_{2.5-10}$ in Guangzhou, China (Guo et al., 2016). Alternatively, cluster 2 consists of Selangor and WP Kuala Lumpur showing positive influence of higher spreading rates with increase in PPT. Budiyono et al. (2016) found that the rainfall had the same pattern with the total acute respiratory infections. Sabah and Sarawak fall at a same high PPT rate $(18 \mathrm{~mm})$ with various spreading rates. From this study, the optimal PPT from 3 to $7 \mathrm{~mm}$ shows the increasing of pandemic spread.

\subsection{Air quality}

Industrial growth, rapid urbanization and rising traffic numbers lead to deterioration of air quality and are threat to both the natural environment and to public health (Mabahwi et al., 2015; Sani, 2006). In Malaysia, the number of industries continues to increase and thus there is an increase in population in both urban and industrial regions (DOS, 2012). The urbanization process led to decrease in air quality based on API indicator (Ling et al., 2010) and also changes in meteorological factors (Chng et al., 2010). Few studies have shown that air pollutants affect the immune response of the lung and inflammatory reactions and that many of these effects underlie the increased risk of respiratory infections (Harrod et al., 2003; Lambert et al., 2003). Hence, an attempt was made to understand the effect of air quality to the pandemic spread in Malaysia at different MCO periods. 


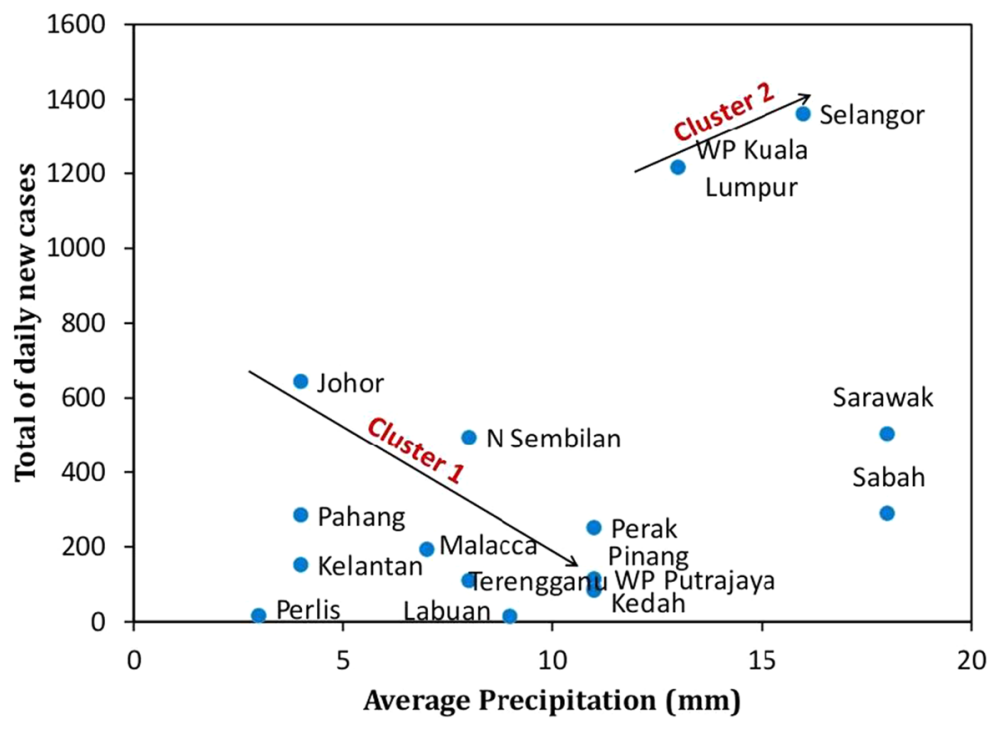

Fig. 5 Average precipitation vs. total of daily new cases

From the figure, good air quality $(<50 \mathrm{AQI})$ was observed throughout Malaysia during MCO phase 3, which records less infected cases. Moderate air quality (>50 AQI) was observed in major cities during MCO phase 1 and 2, particularly in Selangor, WP Kuala Lumpur, WP Putrajaya, Kelantan and Perak (Fig. 6). These cities were considered as highly populated, rapidly urbanized with increasing number of industries, which can be contributed to the moderate air quality. It is also interesting to observe that Pahang, N Sembilan and Sarawak don't show any variations in AQI values in all three MCO periods. The deterioration of air quality is also caused by winds, which bring particulate matter from various locations in the country (Pentamwa \& Oanh, 2008; Steyn \& Castelli, 2010). Additionally, high precipitation during MCO phase 3 period helps to wash out or scattering the pollutants from atmosphere (Comrie, 2007), which has improved the air quality.

\subsection{Correlation and factor analysis}

An attempt was made to understand the influence of meteorological parameters to total cases and total daily new cases recorded at three MCO periods using correlation analysis. In addition, principal component analysis was also applied to the data to identify the key factors controlling the pandemic spread.

In MCO phase 1, T and DP were positively correlated with total cases in most of the states in the country (Table 1). It indicates that increasing $\mathrm{T}$ and DP increases the total number of cases. A positive correlation between $\mathrm{T}$ and severe acute respiratory infections (SARIs) showed that the risk of acute morbidity, particularly among respiratory patients, is up to six times higher for every $1{ }^{\circ} \mathrm{C}$ increase in temperature than in the rest of the population (Silva et al., 2014). In other hand, AQI was negatively correlated with TC, which shows moderate air quality increase the total infected cases. It is interesting to observe that the increase in T and DP promotes the pandemic spread in Selangor and WP Kuala 


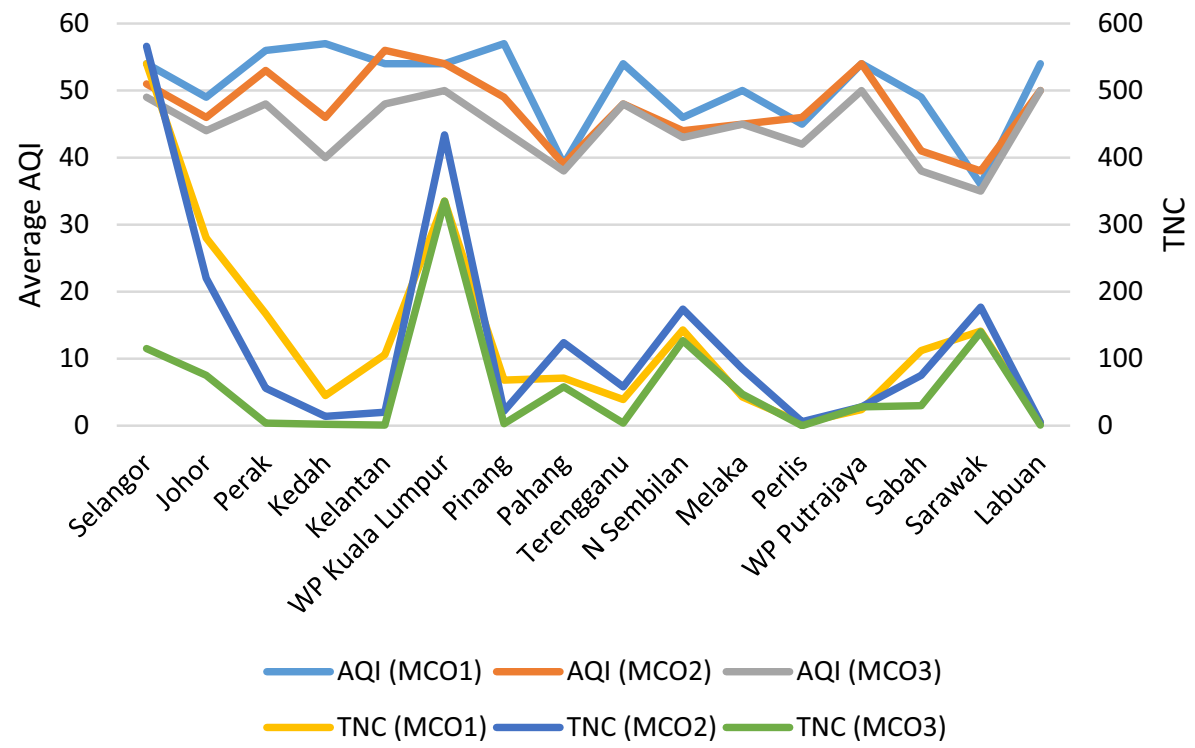

Fig. 6 Average AQI and TNC during MCO periods

Lumpur. In terms of DNC, all the meteorological parameters were either positively or negatively correlated. During phase 1, factor 1 was loaded with TC, DNC, T, RH, DP and PPT, which indicate that T, DP, RH and PPT influence the TC and DNC irrespective of states. Factor 2 and 3 were loaded with TC, DNC, AQI, T and DP, indicating the fact that that air quality also controls the pandemic spread in phase 1 along with $\mathrm{T}$ and DP. The higher temperatures may have increased pollutant concentration, leading to more cases of SARI (Ayres et al., 2009).

In MCO phase 2, PPT, T and DP were negatively correlated with TC in most of the states, which indicate the decreasing of PPT, T and DP increases the number of total infected cases (Table 2). Similarly, PPT, DP and AQI were observed to have a negative correlation with the DNC in few states. It is obvious to note that, $\mathrm{T}$ and $\mathrm{RH}$ are negatively correlated with TC and DNC in Pinang, which shows the decrease in T and RH increases the infected cases. Thus, the lower humidity and temperature during this period with decreased air movement seems to support the development of infectious respiratory diseases (Loh et al., 2011). Similar to phase 1, factor 1 was loaded with TC, DNC, T, RH, PPT and DP, which shows again that these parameters are significantly influencing the pandemic spread across the states. Factor 2 and 3 were loaded with TC, DNC and AQI, which reflects the fact that the air quality also controls the increase in infected cases.

In MCO phase 3, PPT and RH show the positive correlation with TC and DNC, which indicate the increasing of PPT and RH increases the infected cases (Table 3). But T and AQI show negative correlation with the total infected cases. Our results have a coincidence of lower temperatures and a high number of rainy days reflected increasing frequencies of respiratory syncytial virus (RSV) as observed in other countries (Avendano et al., 2003; Chan et al., 2002; Hierholzer et al., 1994; Reese \& Marchette, 1991). DNC were observed to decrease with the increase in PPT and RH in few states. This indicates that higher humidity decreases the survival of viruses (Tang, 2009), whereas the high PPT is generally associated with a decreasing concentration of pollutants through washout process (Comrie, 


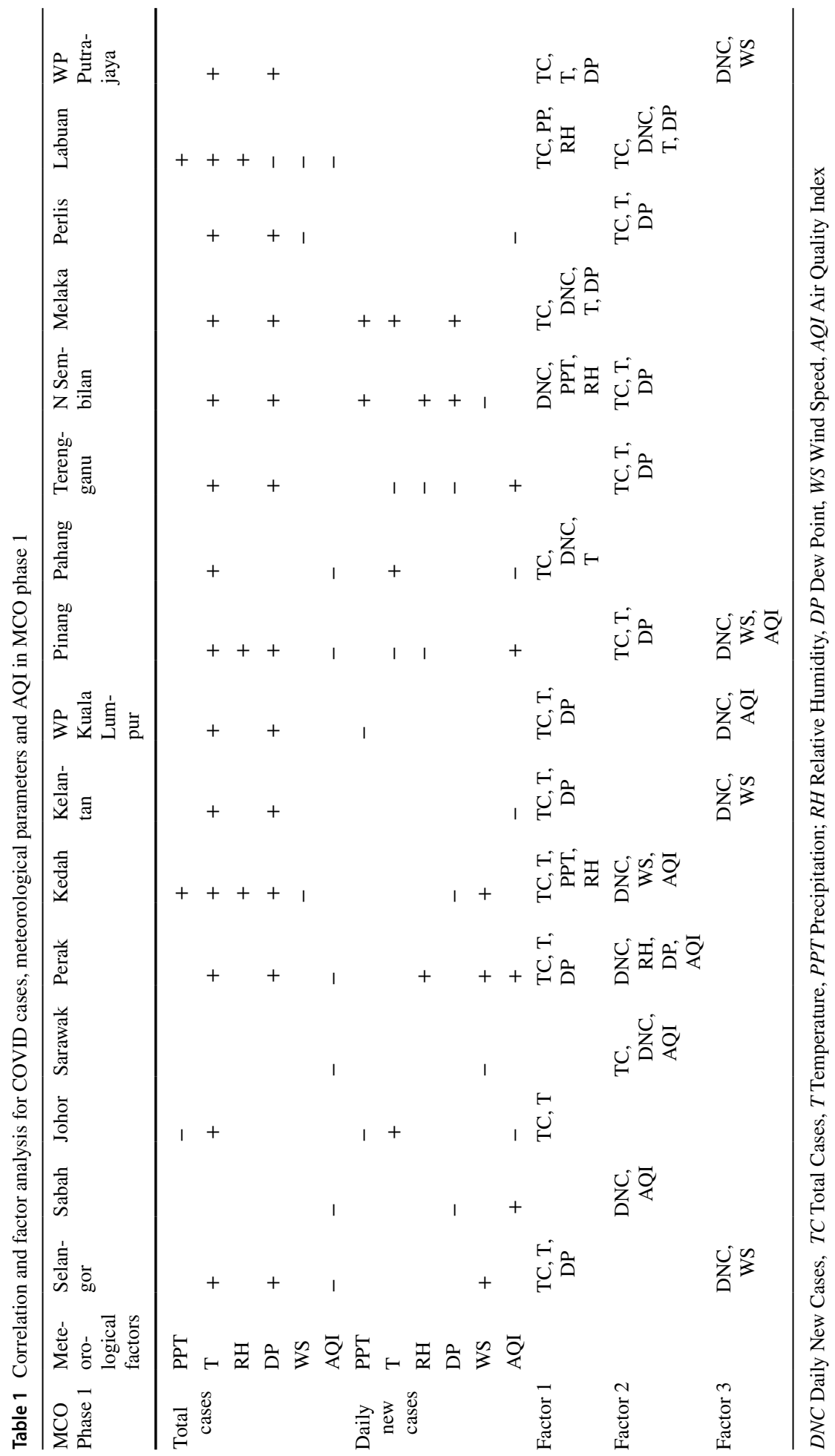




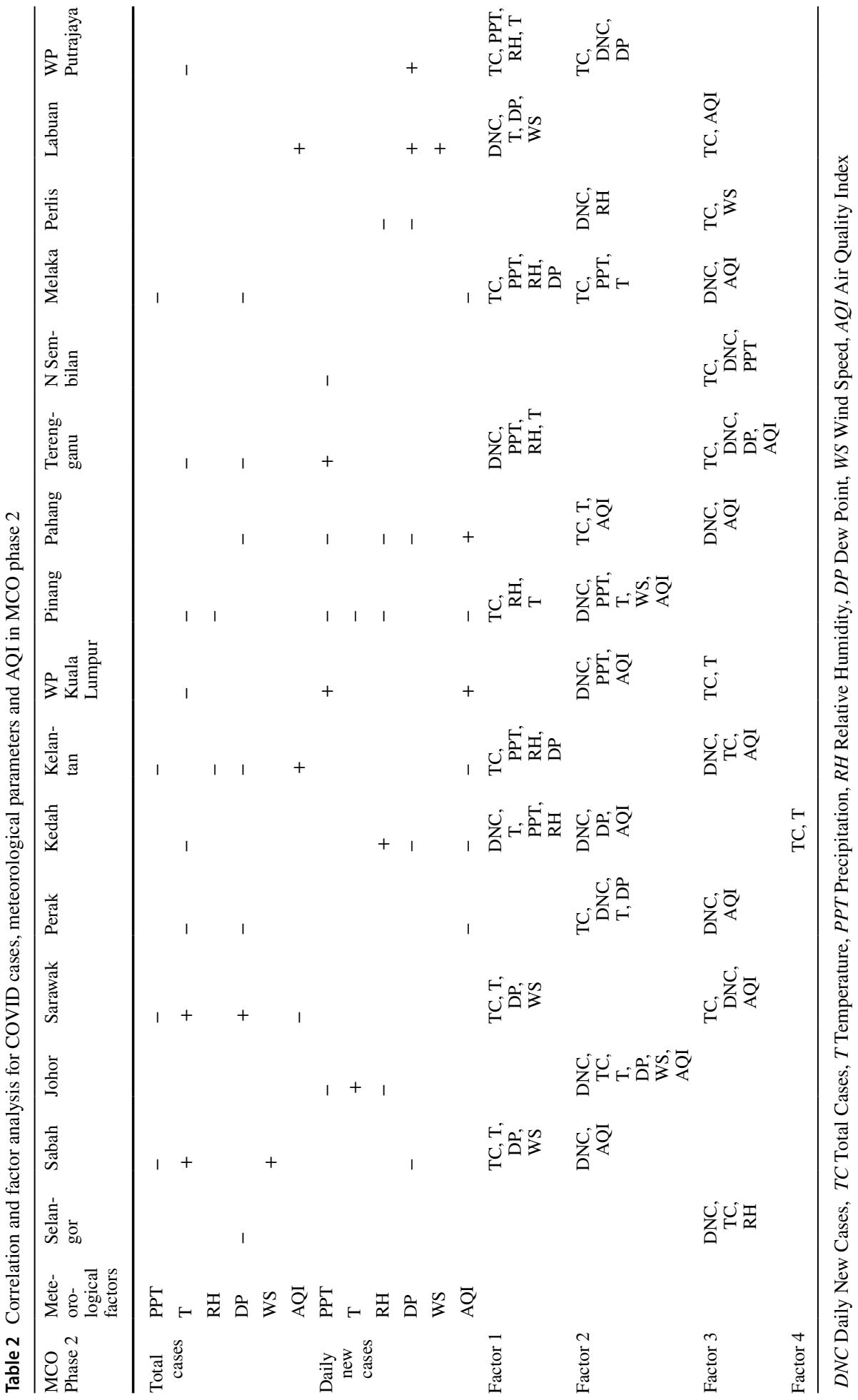


2007). Factor 1 was loaded with TC, DNC, T, RH, PPT, DP and AQI, as the key influencing factors in phase 3. Factor 2 and 3 were loaded TC, DNC, RH and AQI. It is interesting to note that the AQI was influencing in all the three factors which shows the importance of air quality to the pandemic spread.

Summary of the statistical analysis shows that $\mathrm{T}$ and DP play a key role in the pandemic spread during phase 1 and 2. Increasing trend of T and DP triggered the higher infected cases in phase 1 (2123). But decreasing trend of T and DP was not much effective to reduce the number of infected cases in phase 2 (2064). In phase 3, increasing of PPT and RH with good air quality had drastically reduced the infected cases (970).

\subsection{Vulnerable to COVID-19}

From interpretation of data with correlation and factor analysis, it was clearly observed that T, RH, PPT and AQI are the major controlling factors to influencing the pandemic spreading in the country. So, the distribution of infected cases with respect to these parameters was considered to create the vulnerability maps using GIS tool. The analysis was done by the classification of the regions spatially into three categories, as vulnerable, moderate vulnerable and non-vulnerable. Inverse distance weighted (IDW) method was used the average values of TC, T, RH, PPT and AQI to predict the spread of infected cases in the country.

The categories for different parameters were considered as follows: $\mathrm{T}, 23-25{ }^{\circ} \mathrm{C}$ considered as vulnerable; $26-28{ }^{\circ} \mathrm{C}$ as moderate vulnerable and above $28{ }^{\circ} \mathrm{C}$ as non-vulnerable. The spatial map prepared by considering these ranges reflects that Perak, Terengganu, Kelantan, Kedah, Pinang and Perlis in Peninsular Malaysia and Sabah, Sarawak and Labuan in East Malaysia fall under vulnerable zone, even though the total infected cases were comparatively lesser (Fig. 7). Moderate vulnerable zone consists of Pahang, Selangor, WP Kuala Lumpur, WP Putrajaya, Melaka, N Sembilan and Sarawak. Johor is considered as a non-vulnerable zone, which has high $T\left(29^{\circ} \mathrm{C}\right)$ recorded in the country. It is clearly observed that there is an increase in $T$ from northern to southern Peninsular Malaysia, where the vulnerable zone is in northern Peninsular States with comparatively low $T$ condition. The increasing mortality rate was strongly associated with low $\mathrm{T}$ in this region (Dadbakhsh et al., 2017; Fallah \& Mayvaneh, 2016).

$\mathrm{RH}$ ranging from 70 to $80 \%$ is considered as vulnerable, $80-90 \%$ as moderate vulnerable and above $90 \%$ as non-vulnerable. Most of the states in Peninsular Malaysia represented vulnerable zone with low RH and Perlis had the lowest RH in the country (Fig. 8). The two main states (Sabah and Sarawak) in East Malaysia were under non-vulnerable region with high $\mathrm{RH}$. Lower RH was inferred to increase the spreading rate, which was observed in Peninsular Malaysia compared to East Malaysia. Similar observation was also made that during the spread of influenza virus as the spread increased in low humidity condition (Lowen et al., 2007).

PPT values ranging from 3 to $7 \mathrm{~mm}$ were considered as vulnerable, $7-11 \mathrm{~mm}$ as moderate vulnerable and above $11 \mathrm{~mm}$ as non-vulnerable. Johor, Pahang, Kelantan and Perlis fall under vulnerable zone due to the low PPT, in which the infected cases were significant (Fig. 9). Moderate vulnerable regions were Kedah, Pinang, Perak, Terengganu, N Sembilan, Melaka and Labuan, which occupies most of the areas in Peninsular Malaysia. Nonvulnerable zone was dominated in East Malaysia (Sarawak and Sabah), where high PPT was recorded compared to Peninsular Malaysia due to the different geographic locations and weather patterns. It is interesting to note that Selangor, WP Kuala Lumpur and WP Putrajaya were in non-vulnerable zone with respect to PPT though high number of infected 


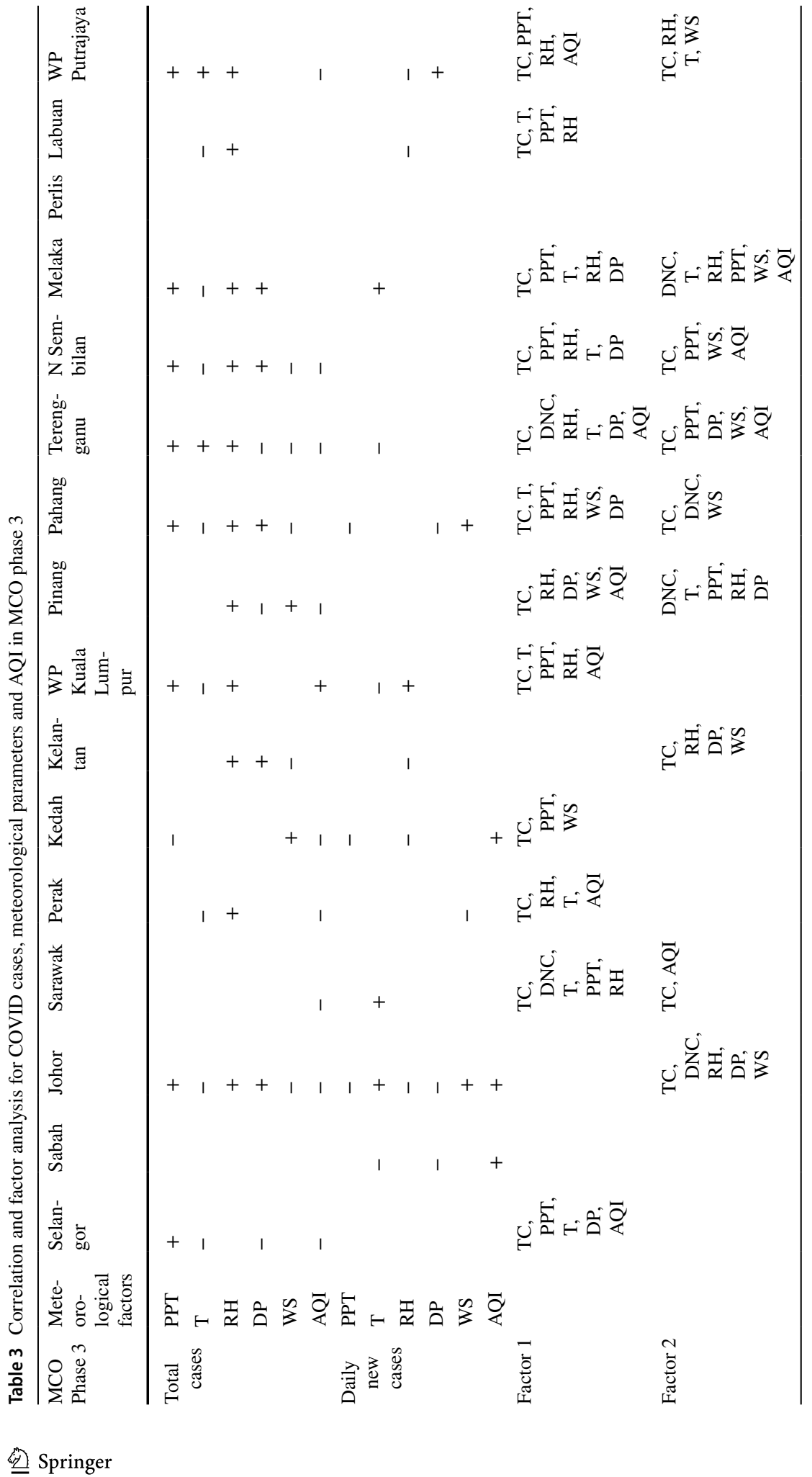




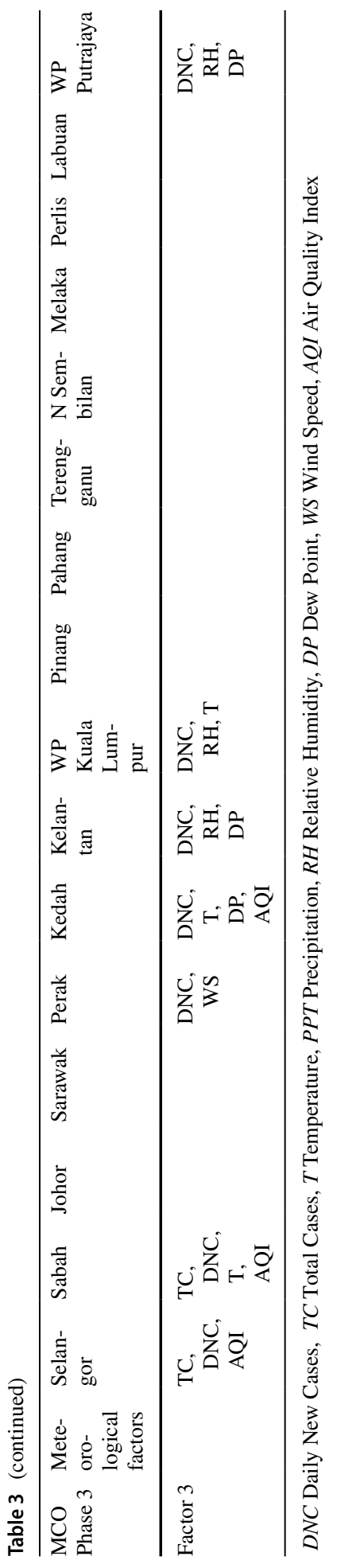



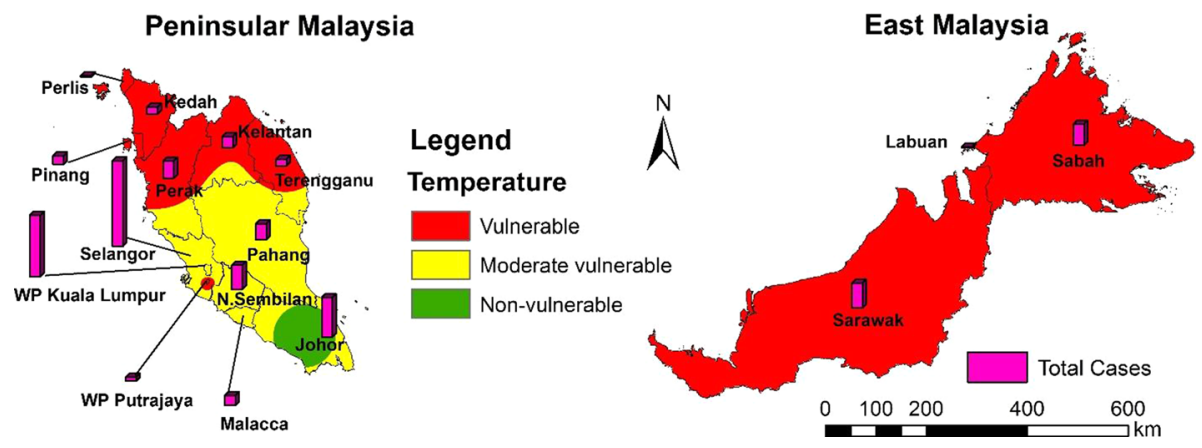

Fig. 7 Vulnerable map for temperature
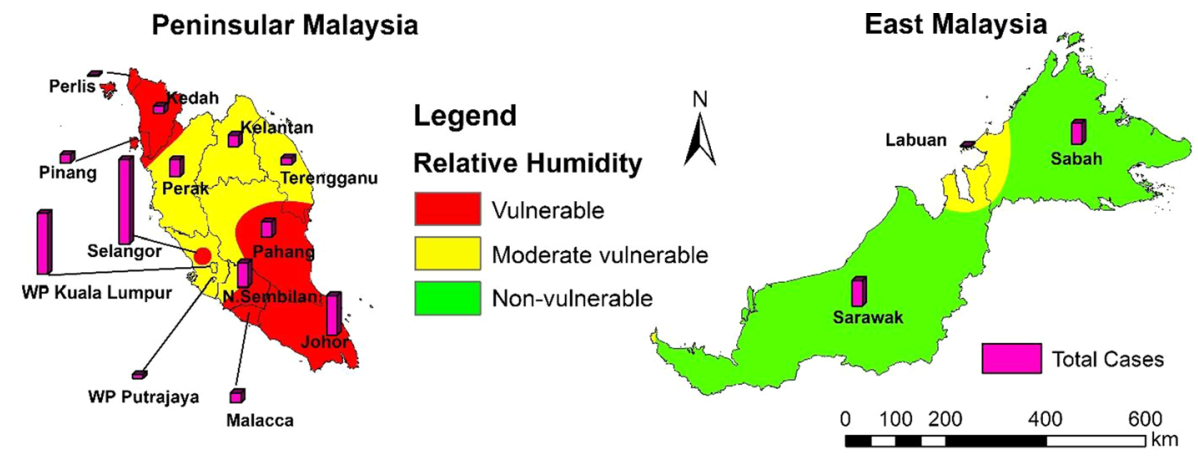

Fig. 8 Vulnerable map for relative humidity
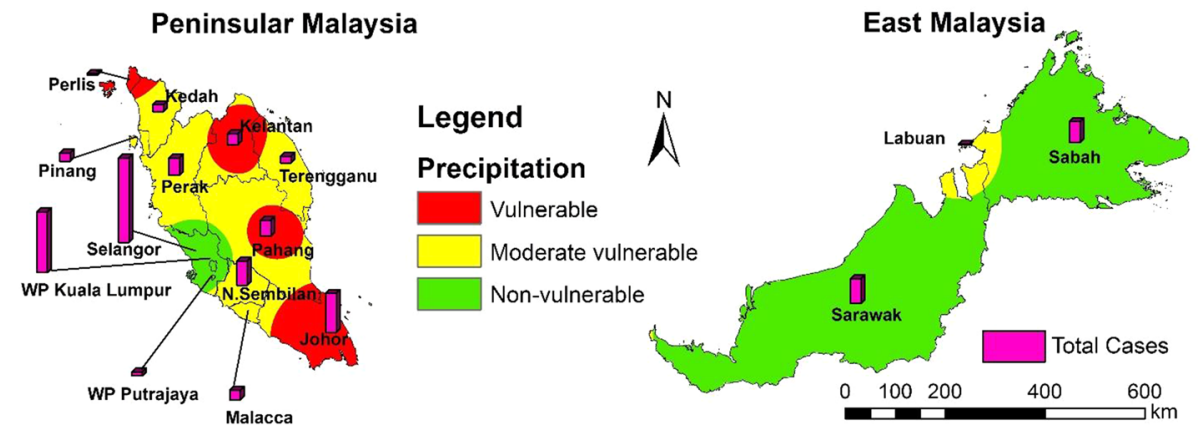

Fig. 9 Vulnerable map for precipitation

cases was observed. Hence, it is noticed that the high PPT can also reduce the total infected cases in East Malaysia, compared to Peninsular Malaysia due to washout effect of atmospheric pollutants.

AQI values ranging from 50 and above are considered as vulnerable, 50-45 as moderate vulnerable and below 45 as non-vulnerable. It was clearly observed that Selangor, WP Kuala Lumpur, WP Putrajaya, Perak and Kelantan are considered as vulnerable zone 

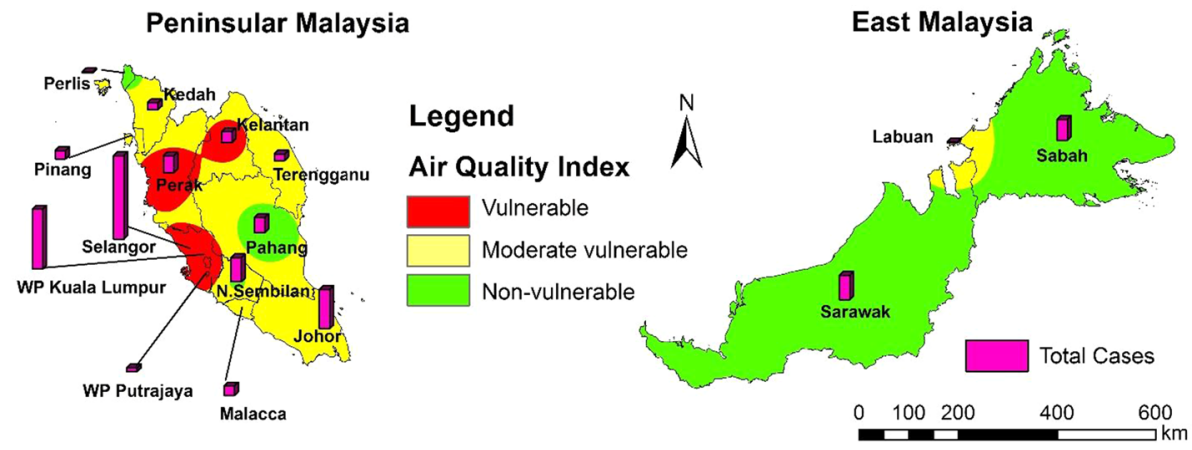

Fig. 10 Vulnerable map for air quality index
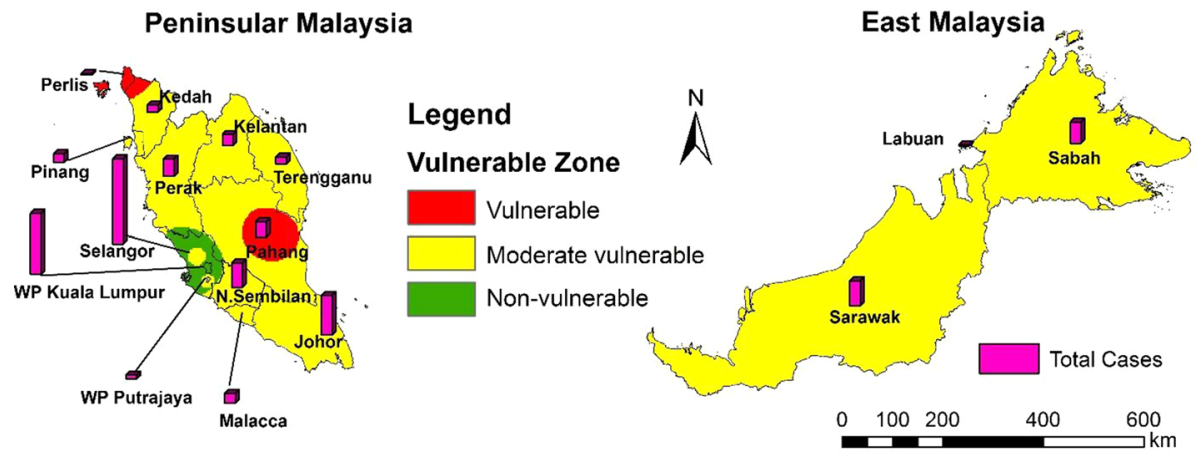

Fig. 11 Integrated vulnerable map for Malaysia

(Fig. 10). These are the key cities in Peninsular Malaysia which contribute poor air quality due to their rapid urbanization, industries and high density of automobiles (Ling et al., 2010). Pahang and Perlis are considered as non-vulnerable regions. Most of the regions in East Malaysia are indicated as non-vulnerable category. Since East Malaysia is with Borneo rain forest, it reflects the less industrial activities, thus maintaining good air quality. In addition, high rainfall in this region may also washout the atmospheric pollutants (Guo et al., 2016; Ouyang et al., 2015).

A consolidated vulnerable zone demarcation map was also prepared by overlying mean T, RH, PPT and AQI with total infected cases (Fig. 11). It is obvious to see that Perlis and Pahang regions represent the vulnerable zone, with decrease in RH, T and PPT triggered high infected cases. It is interesting to observe that Selangor, WP Kuala Lumpur and WP Putrajaya fall in non-vulnerable to moderately vulnerable regions. In these regions, the variations of each meteorological parameter control the pandemic spread. The whole East Malaysia is considered as moderate vulnerable zone, with increase in RH, PPT and a decrease in AQI reflecting good air quality supports the reduction of the spread.

\subsection{Time series analysis}

In order to observe the effect of infected cases in three MCO periods with respect to meteorological parameters and air quality, a time series analysis on spatial distribution of $\mathrm{T}$, 
RH, PPT and AQI was attempted. The average values of total daily new cases, T, RH, PPT and AQI, were considered during these MCO periods.

The spatial distribution of $\mathrm{T}$ and $\mathrm{RH}$ shows a decreasing trend from northern to southern Peninsular Malaysia during MCO phase 1 (Fig. 12). Hence, the low T and RH support the high infected cases in southern Peninsular Malaysia (Liu et al., 2016). In other hand, moderate air quality was observed in northern Peninsular Malaysia, which had increased the spread. In East Malaysia, all the meteorological parameters show decreasing trend which supports the infected cases. But, interestingly good air quality was observed, which has suppressed the spreading rate compared to Peninsular Malaysia.

In MCO phase 2, few states (Kedah, Perak, Pinang, Terengganu) in northern Peninsular Malaysia noted to have a lesser RH with poor air quality leading to the increase in infected cases (Silva et al., 2013; Masoumi et al., 2017). But in southern Peninsular Malaysia, increasing trend of T, RH and poor air quality triggered the spreading rate (Fig. 13). It is interesting to note that the major cities, Selangor, WP Kuala Lumpur and WP Putrajaya, show low $\mathrm{T}$ and RH, which has high infected cases. In East Malaysia, Sabah and Sarawak have almost same range of values in all meteorological parameters, but low infected cases were recorded in Sabah, due to the influence of high PPT from Labuan.

Overall, the number of infected cases in MCO phase 3 drastically reduced from MCO phase 1 and 2. High RH and good air quality were observed in northern Peninsula, whereas high RH and T in southern Peninsula greatly support to reduce the total infected cases (Fig. 14). In East Malaysia, high RH, PPT and good air quality suppressed the infected cases during MCO phase 3. Almost similar values of T, RH, PPT and AQI were noted in Sarawak and Sabah; higher total infected cases were recorded in Sarawak compared to Sabah. This indicates that other factors such as social distancing and individual immune system may also affect the spread and mortality in East Malaysia.

\subsection{CoV-2 mutation}

SARS-CoV-2 belongs to Betacoronavirus (betaCoV) and results in a respiratory disorder leading to mortality of $10 \%$ and it is more sensitive to ultraviolet rays and temperature (Chan et al., 2013). Devoted sgRNAs translate the distinct accessory and structural proteins in various CoVs. The disease reversion and the potential pandemic nature depend on viral mutation (Cascella et al., 2020). The spike mutation indicated that D614G was the
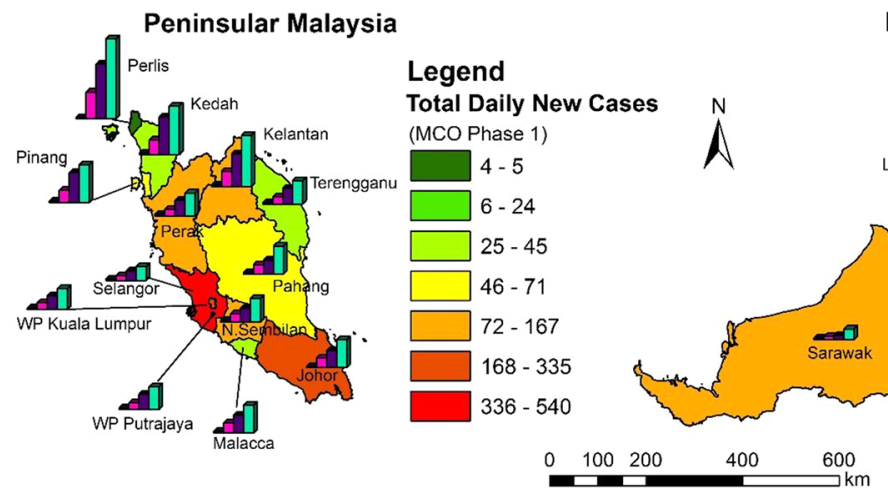

East Malaysia

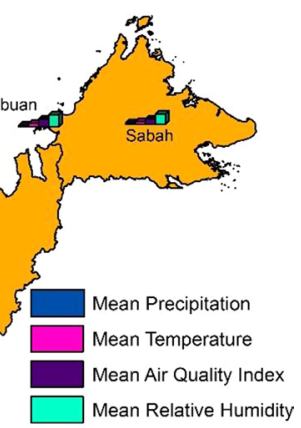

Fig. 12 Time series map for MCO phase 1 


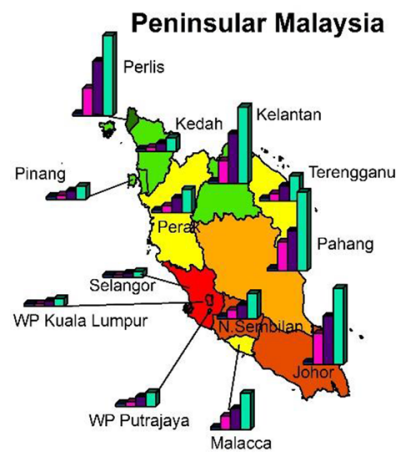

\section{East Malaysia}

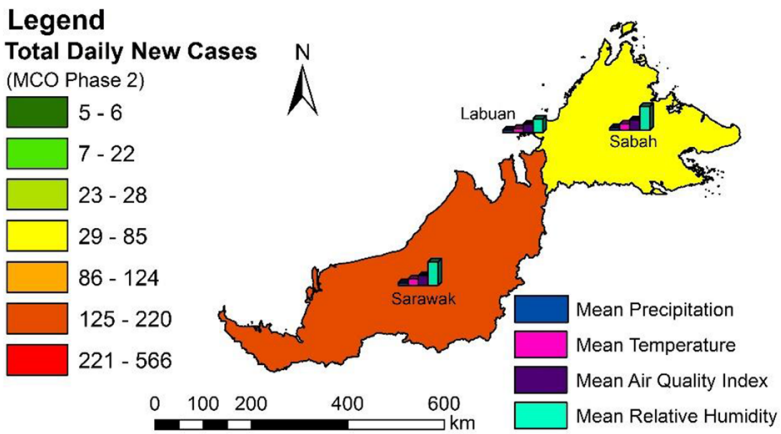

Fig. 13 Time series map for MCO phase 2
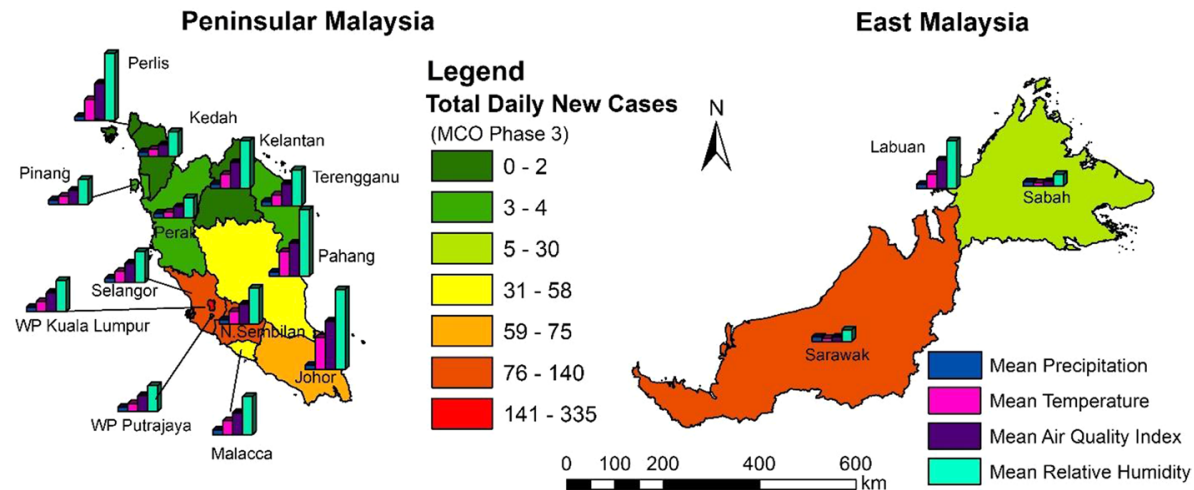

Fig. 14 Time series map for MCO phase 3

predominant spike observed globally (Korber et al., 2020). D614G mutation has resulted in the global pandemic leading to a great impact on potential immunity with enhanced transmissibility.

Based on a global analysis of D614 G mutation (Korber et al., 2020), the D614 variant had been the dominant local type early in the epidemic before March 1. However, in just a few weeks, G614 was the dominant local form in a matter. Asian samples were dominated by the original Wuhan D614 form through mid-March but the G614 form was clearly observed and expanded in Asian countries outside China by mid-March.

In Malaysia, only D614 form was reported from prior to March to mid-March based on GISAID data (www.cov.lanl.gov). Hence, an attempt was made to identify the survival capacity of D614 mutant with respect to the meteorological factors during the study period. It was clearly observed that D614 mutant was dominance prior to March, followed by a sudden weakening in early March and gradually decreasing toward April (Fig. 15). D614 mutant survival trend was also facilitated by the variation in T, RH, PPT and air quality. 


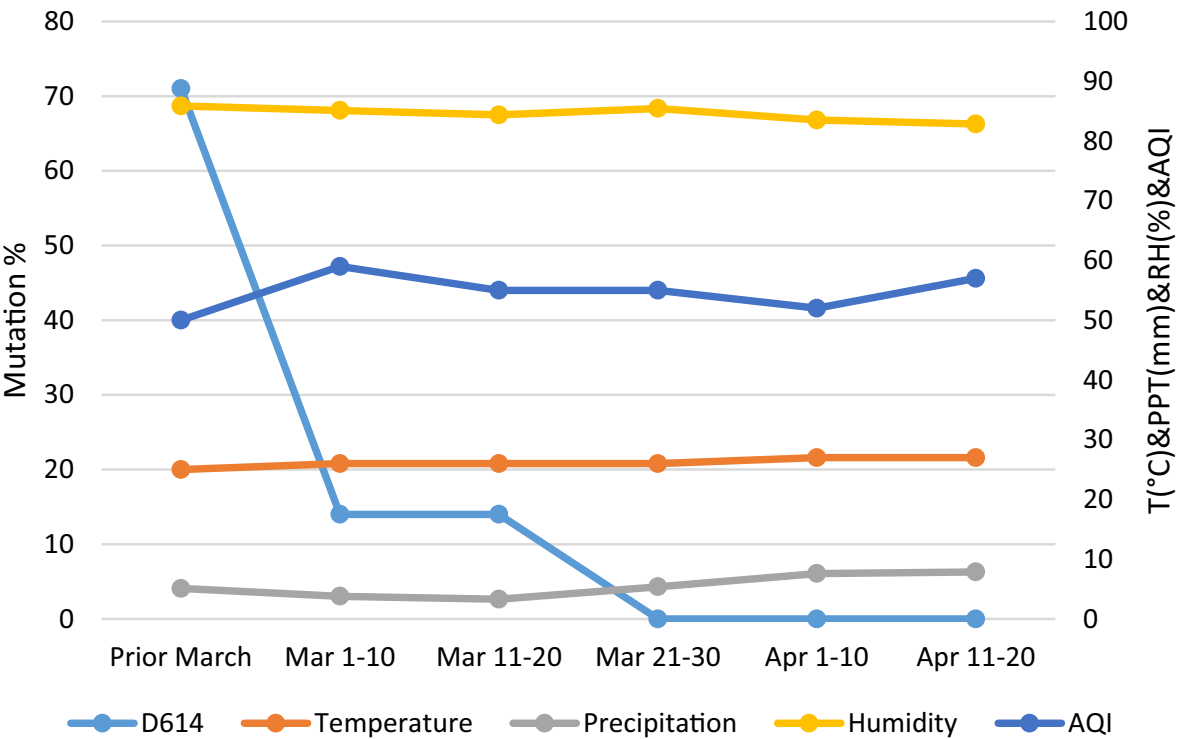

Fig. 15 Survival of D614 mutant under various conditions of meteorological factors and AQI

The figure shows that $1{ }^{\circ} \mathrm{C}$ increase in $\mathrm{T}, 1 \%$ drop in $\mathrm{RH}$ and $1 \mathrm{~mm}$ decrease in PPT has weakened D614 mutant during 1-10 March. Similarly, increasing T and PPT and decreasing RH further weakened D614 mutation from mid of March to April. The SARS-CoV is heat sensitive, high temperature and humidity make it hard to survive (Shaman et al., 2009; Bunket et al., 2016), and sudden variation in the rapid increase in the respiratory mortality is due to variation in temperature (Zhan et al., 2017). Influenza seasonality is probably dictated in part by weather patterns (Chattopadhyay et al., 2018). It is interesting to observe that moderate air quality (AQI > 50) weakened D614 mutation during early March, and good air quality $(\mathrm{AQI}<50)$ further weakened D614 mutation during end of March. Hence, it is inferred that the seasonal variation of air quality also controls the survival capacity of D614 variant.

\section{Conclusion}

This study investigated the effects of meteorological parameters and air quality to COVID19 pandemic spreading during three MCO phases in Malaysia. The increasing trend of total infected cases was observed in MCO phases 1 and 2, and the DNC decreased in MCO phase 3. Positive correlation among increasing infected cases and high population density in major cities of Peninsular Malaysia show the population density is also a controlling factor for spreading apart from meteorological influences. Interpretation of data reveals that $\mathrm{T}$, RH, PPT and air quality are the main controlling factors to the pandemic spread across all the states in the country. The optimal $\mathrm{T}$ between 23 and $25^{\circ} \mathrm{C}$ has recorded high number of spreading particularly in central and northern Peninsular Malaysia, apart from other factors such as population density, social distancing and immune system of individuals. The average $\mathrm{RH}$ in most of the states has negatively associated with spreading rates. Through correlation and factor analysis, it was observed that $\mathrm{T}$ and DP play a key role in the pandemic 
spread during MCO phase 1 and 2. Increasing of T, RH, PPT and good air quality has drastically reduced the infected cases during MCO phase 3 . Vulnerable regions in central and northern Peninsular Malaysia are mainly influenced by low T, RH, PPT and moderate air quality. In East Malaysia, high RH, PPT and good air quality control the pandemic spread. Time series spatial analysis indicates that most of the key parameters (RH, T, PPT and AQI) has favored to the decreasing of infected cases in MCO phase 3. CoV-2 mutation shows that $1{ }^{\circ} \mathrm{C}$ increase in $\mathrm{T}, 1 \%$ drop in $\mathrm{RH}$ and $1 \mathrm{~mm}$ decrease in PPT have weakened the D614 mutant during early March. Increasing trend of T, PPT and good air quality has further decreased the variant at the end of March. Hence, the study infers that pandemic spread is controlled by T, RH and air quality in Peninsular Malaysia, whereas RH, PPT and air quality in East Malaysia. The baseline data produced from this research provide the initial report on the state-wise spreading trend in the entire country. The outcome of the study will help to improve the precautionary measures in the identified vulnerable regions for the next wave of COVID-19 pandemic or related epidemic diseases.

Supplementary Information The online version contains supplementary material available at https://doi. org/10.1007/s10668-021-01719-z.

Acknowledgements The authors would like to thank the anonymous reviewers for their constructive comments to further improve the quality of the manuscript.

\section{References}

Abdullah, S. (1993). Coastal Developments in Malaysia -Scope, Issues and Challenges. Department of Irrigation and Drinage, Malaysia.

Abdullah, J.M., Wan Ismail, W.F.N., Mohamad, I., Ab Razak A., Harun, A., Musa, K.I., \& Lee, Y.Y. (2020). A critical appraisal of COVID-19 in Malaysia and beyond. The Malaysian Journal of Medical Sciences. 27(2), 1-9. https://doi.org/10.21315/mjms2020.27.2.1.

Ahmed, W., Payyappat, S., Cassidy, M., Harrison, N., \& Besley, C. (2020). Sewage-associated marker genes illustrate the impact of wet weather overflows and dry weather leak- age in urban estuarine waters of Sydney, Australia. Science of the Total Environment 705, 135390.

Anderson, R., \& May, R. (1991). Infectious Diseases of Humans: Dynamics and Control. Oxford University Press.

Asyary, A., \& Veruswati, M. (2020). Sunlight exposure increased Covid-19 recovery rates: A study in the central pandemic area of Indonesia. Science of the Total Environment, 729, 139016. https://doi.org/10. 1016/j.scitotenv.2020.139016

Avendano, L. F., Parra, J., Padilla, C., \& Palomino, M. A. (2003). The influence of winter 2002 in pediatric health: Dissociation between environmental factors and respiratory syncytial viruses, in Santiago. Revista Medica De Chile, 131, 902-908.

Ayres, J. G., Forsberg, B., Annesi-Maesano, I., et al. (2009). Climate change and respiratory disease: European Respiratory Society position statement. European Respiratory Journal, 34, 295-302.

Azlan., Arina Anis., Hamzah Mohammad Rezal., Jen Tham Id Sern., \& Hadi, Suffian Id Ayub. (2020). Public knowledge, attitudes and practices towards COVID-19: A cross-sectional study in. PLoS ONE. https://doi.org/10.1371/journal.pone.0233668

Bagyaraj, M., Shankar, K., Alemayehu, T., Muthukumarasamy, R., \& Gnanachandrasamy, G. (2020). Distribution and trend analysis of COVID-19 in India: Geospatial approach. Journal of Geographical Studies., 4(1), 1-9. https://doi.org/10.21523/gcj5.20040101

Barreca, A. I. (2012). Climate change, humidity, and mortality in the United States. Journal of Environmental Economics and Management, 63(1), 19-34. https://doi.org/10.1016/j.jeem.2011.07.004

Barreca, A.I. \& Shimshack, J.P. (2012). Absolute humidity, temperature, and influenza mortality: 30 years of county-level evidence from the United States. The American Journal of Epidemiology 176, suppl_7, S114-S122. https://doi.org/10.1093/aje/kws259. 
Bartzokas, A., Kassomenos, P., Petrakis, M. \& Celessides, C. (2004). The effect of meteorological and pollution parameters on the frequency of hospital admissions for cardiovascular and respiratory problems in Athens. Indoor and Build Environment, 13, 271-275.

Begon, M., Bennett, M., Bowers, R., French, N., Hazel, S., \& Turner, J. (2002). A clarification of transmission terms in host-microparasite models: Numbers, densities and areas. Epidemiology and Infection, $129,147$.

Biktasheva, I. V. (2020). Role of a habitat's air humidity in Covid-19 mortality. Science of the Total Environment. https://doi.org/10.1016/j.scitotenv.2020.138763

Braat, J. P., Mulder, P. G., Duivenvoorden, H. J., Gerth Van Wijk, R., Rijntjes, E., \& Fokkens, W. J. (2002). Pollutional and meteorological factors are closely related to complaints on non-allergic, non-infectious perennial rhinitis patients: A time series model. Clinical and Experimental Allergy, 32, 690-697.

Budiyono, Rismawati, S.P., Jati, \& Ginandjar, P. (2016). Potential impact of climate variability on respiratory diseases in infant and children in Semarang. IOP Conference Series: Earth and Environmental Science, 55, 012049.

Cascella, M., Michael Rajnik., Arturo Cuomo., Scott, C., Dulebohn., Raffaela, Di., \& Napoli. (2020). Features, Evaluation and Treatment Coronavirus (COVID-19) - Stat Pearls - NCBI Bookshelf. https:// www.ncbi.nlm.nih.gov/books/NBK554776/?report=printable1/16.

Cengiz, T., \& Akbulak, C. (2009). Application of analytical hierarchy process and geographic informationsystems in land-use suitability evaluation: a case study of Dümrek village (Çanakkale, Turkey). International Journal of Sustainable Development \& World Ecology, 16(4), 286-294.

Chan, P. W., Chew, F. T., Tan, T. N., Chua, K. B., \& Hooi, P. S. (2002). Seasonal variation in respiratory syncytial virus chest infection in the tropics. Pediatric Pulmonology, 34, 47-51.

Chan, J. F., To, K. K., Tse, H., Jin, D. Y., \& Yuen, K. Y. (2013). Interspecies transmission and emergence ofnovel viruses: lessons from bats and birds. Trends in Microbiology, 21(10), 544-555.

Chattopadhyay, I., Kiciman, E., Elliott, J. W., Shaman, J. L., \& Rzhetsky, A. (2018). Conjunction of factors triggeringwaves of seasonal influenza. eLite, 7, e30756. https://doi.org/10.7554/eLife.30756.

Che Mat NF., Edinur HA., Abdul Razab MKA., \& Safuan S. (2020). A single mass gathering resulted in massive transmission of COVID-19 infections in Malaysia with further international spread. Journal of Travel Medicine. 1-4.

Chen, N., Zhou, M., Dong, X., Qu, J., Gong, F., Han, Y., Qiu, Y., Wang, J., Liu, Y., \& Wei, Y. (2020). Epidemiological and clinical characteristics of 99 cases of 2019 novel coronavirus pneumonia in Wuhan, China: A descriptive study. Lancet, 395, 507-513. https://doi.org/10.1016/S0140-67362030211-7

Childs, C. (2004). Interpolating surfaces in ArcGIS spatial analyst. ArcUser, 3235, 569.

Chng, L. K., Abdullah, A. M., Sulaiman, W. N. A., \& Ramli, M. F. (2010). The effects of improved land use on the meteorological medeling in klang Valley region Malaysia. Environment Asia, 3, 117-123.

Coccia, M. (2020). Factors determining the diffusion of COVID-19 and suggested strategy to prevent future accelerated viral infectivity similar to COVID. Science of the Total Environment., 729, 138474. https:// doi.org/10.1016/j.scitotenv.2020.138474

Comrie, A. (2007). Climate change and human health. Geography Compass 1/3, 325-339.

Dadbakhsh, M., Khanjani, N., Bahrampour, A., \& Haghighi, P. S. (2017). Death from respiratory diseases and temperature in Shiraz, Iran 2006-2011. International Journal of Biometeorology, 61(2), 239-246. https://doi.org/10.1007/s00484-016-1206-z

Falagas, M. E., Theocharis, G., Spanos, A., Vlara, L. A., Issaris, E. A., Panos, G., \& Peppas, G. (2008). Effect of meteorological variables on the incidence of respiratory tract infections. Respiratory Medicine, 102, 733-737. https://doi.org/10.1016/j.rmed.2007.12.010.

De Jong, M. C. M., Diekmann, O., \& Heesterbeek, J. A. P. (1995). How does transmission of infection depend on population size? Publications of the Newton Institute, 5, 84-94. Cambridge University Press.

Department of Environment Malaysia (DOE) (1997). A guide to air pollutionIndex in malaysia (API). Ministry of Science, Technology and Environment, Kuala Lumpur.

Department of Environment Malaysia (DOE) (2012). Malaysia environmental quality report. Ministry of Science, Technology andEnvironment, Kuala Lumpur.

Dominick, D., Juahir, H., Latif, M. T., Zain, S. M., \& Aris, A. Z. (2012). Spatial assessment of air quality patterns in Malaysia using multivariate analysis. Atmospheric Environment, 60, 172-181.

DOS. (2012). Annual report 2012. Department of Statistics DOS.

Duhanyan, N., \& Roustan, Y. (2011). Below-cloud scavenging by rain of atmospheric gases and particulates. Atmospheric Environment, 45, 7201-7217.

Fallah, G.G., \& Mayvaneh, F. (2016). Effect of air temperature and universal thermal climate index on respiratory diseases mortality in Mashhad, Iran. The Archives of Iranian Medicine 19(9), 618-624 . 
Ferrari, M., Perkins, S., Pomeroy, L., \& Bjornstad, O. (2011). Pathogens, social networks, and the paradox of transmission scaling. Interdisciplinary Perspectives on Infectious Disease. 2, 267049

Garnier-Crussard, A., Forestier, E., Gilbert, T., \& Krolak-Salmon, P. (2020). Novel coronavirus (COVID19) epidemic: What are the risks for older patients? Journal of the American Geriatrics Society. https://doi.org/10.1111/jgs.16407.

Gómez-Acebo, I., Llorca, J., \& Dierssen, T. (2013). Cold-related mortality due to cardiovascular diseases, respiratory diseases and cancer: A case-crossover study. Public Health, 127(3), 252-258. https://doi. org/10.1016/j.puhe.2012.12.014

Guo, L.-C., Zhang, Y., Lin, H., Zeng, W., Liu, T., Xiao, J., Rutherford, S., You, J., \& Ma, W. (2016). The washout effects of rainfall on atmospheric particulate pollution in two Chinese cities. Environmental Pollution, 215, 195-202. https://doi.org/10.1016/j.envpol.2016.05.003.

Guo, C., Bo, Y., Lin, C., Li, H.B., Zeng, Y., Zhang, Y., Hossain, M.S., Chan, J.W.M., Yeung, D.W., Kwok, K-O., Wong, S.Y.S., Lau, A.K.H., \& Lao, X.Q. (2021). Meteorological factors and COVID-19 incidence in 190 countries: An observational study. Science of the Total Environment, 757, 143783.

Harrod, K. S., Jaramillo, R. J., Rosenberger, C. L., et al. (2003). Increased susceptibility to RSV infection by exposure to inhaled diesel engine emissions. American Journal of Respiratory Cell and Molecular Biology, 28, 451-463.

Hierholzer, J. C., Tannock, G. A., \& Hierholzer, C. M. (1994). Subgrouping of respiratory syncytial virus strains from Australia and Papua Guinea by biological and antigenic characteristics. Archives of Virology, 136, 133-147.

Hopman, J., Allegranzi, B., \& Mehtar, S. (2020). Managing COVID-19 in Low- and Middle-Income Countries. JAMA, 323(16), 1549-1550. https://doi.org/10.1001/jama.2020.4169.

Hu, H., Nigmatulina, K., \& Eckhoff, P. (2013). The scaling of contact rates with population density for the infectious disease models. Mathematical Biosciences., 244, 125-134.

Huang, C., Wang, Y., Li, X., Ren, L., Zhao, J., Hu, Y., Zhang, L., Fan, G., Xu, J., Gu, X., Cheng, Z., Yu, T., Xia, J., Wei, Y., Wu, W., Xie, X., Yin, W., Li, H., Liu, M., Xiao, Y., Gao, H., Guo, L., Xie, J., Wang, G., Jiang, R., Gao, Z., Jin, Q., Wang, W., Cao, B. (2020). Clinical features of patients infected with 2019 novel coronavirus in Wuhan, China. Lancet, 395, 497-506. https://doi.org/10.1016/S0140-67362 030183-5

Ismail, A. Z., Abdullah, A. M., \& Samah, M. A. A. (2017). Environmetric study on air quality pattern for assessment in Northern region of Peninsular Malaysia. Journal of Environmental Science and Technology, 10, 186-196.

Jain, M., Sharma, G.D., Goyal, M., Kaushal, R., \& Sethi, M. (2021). Econometric analysis of COVID19 cases, deaths, and meteorological factors in South Asia. Environmental Science and Pollution Research, pp 1-17.

Korber, B., Fischer, W., Gnanakaran, S., Yoon, H., Theiler, J., Abfalterer, W., Foley, B,, Giorgi, E. E., Bhattacharya, T., Parker, M. D., Partidge, D. G., Evans, C. M., de Silva, T., Labranche, C. C., \& Montefiori, D. C. (2020). Spike mutation pipeline reveals the emergence of a more transmissible form of SARSCoV-2. bioRxiv. https://doi.org/10.1101/2020.04.29.069054

Kumar, S. (2020). Effect of meteorological parameters on spread of COVID-19 in India and air quality during lockdown. Science of the Total Environment., 745, 141021.

Lambert, A.L., Mangum, J.B., DeLorme, M.P., \& Everitt, J.I. (2003). Ultrafine carbon black particles enhance respiratory syncitial virus-induced airway reactivity, pulmonary inflammation, and chemokine expression. Toxicol Sci. 73, 339-348.

Lieberman, D., \& Friger, M. D. (1999). Seasonal variation in hospital admissions for community-acquired pneumonia: A 5-year study. Journal of Infection, 39, 134-140.

Ling, O. H. L., Ting, K. H., Shaharuddin, A., Kadaruddin, A., \& Yaakob, M. J. (2010). Urban growth and air quality in Kuala Lumpur city, Malaysia. Environment Asia., 3, 123-128.

Liu, Y., Liu, J., Chen, F., Shamsi, B. H., Wang, Q., Jiao, F., Qiao, Y., \& Shi, Y. (2016). Impact of meteorological factors on lower respiratory tract infections in children. Journal of International Medical Research., 441, 30-41.

Loh, T. P., Lai, F. Y., Tan, E. S., et al. (2011). Correlations between clinical illness, respiratory virus infections and climate factors in a tropical paediatric population. Epidemiology and Infection, 139, 1884-1894.

Lowen, A. C., Mubareka, S., Steel, J., \& Palese, P. (2007). Influenza virus transmission is dependent on relative humidity and temperature. PLoS Pathogens, 3(10), 1470-1476. https://doi.org/10.1371/journ al.ppat.0030151

Lu, H., Stratton, C. W., \& Tang, Y. W. (2020). Outbreak of pneumonia of unknown etiology in Wuhan China: The Mystery and the Miracle. Journal of Medical Virology. https://doi.org/10.1002/jmv.25678 
Ma, Y., Zhao, Y., Liu, J., He, X., Wang, B., Fu, S., Yan, J., Niu, J., Zhou, J., \& Luo, B. (2020). Effects of temperature variation and humidity on the death of COVID-19 in Wuhan, China. Science of the Total Environment., 138226,. https://doi.org/10.1016/j.scitotenv.2020.138226

Mabahwi, N. S., Leh, O. L. H., \& Omar, D. (2015). Urban air quality and human health effects in Selangor, Malaysia. Procedia - Social and Behavioral Sciences., 170(27), 282-291.

Macfarlane, A. (1977). Daily mortality and environment in English conurbations. Air pollution, low temperature, and influenza in Greater London. British Journal of Preventive \& Social Medicine, 31(1), 54-61. https://doi.org/10.1136/jech.31.1.54.

Masoumi, K., Shoushtari, M. H., Forouzan, A., Darian, A. A., Dastoorpoor, M., Ebrahimzadeh, P., \& Aghababaeian, H. (2017). Rainfall-associated Bronchospasm epidemics: The epidemiological effects of air pollutants and weather variables. Canadian Respiratory Journal. https://doi.org/10.1155/2017/ 9252069

Mc Callum, H., Barlow, N., \& Hone, J. (2001). How should pathogen transmission be modelled? Trends in Ecology \& Evolution., 16, 295.

Mohsen, A., Sharifi, A., Dorosti, S., Ghoushchi, S. J., \& Ghanbari, N. (2020). Investigation of effective climatology parameters on COVID-19 outbreak in Iran. Science of the Total Environment., 729, 138705. https://doi.org/10.1016/j.scitotenv.2020.138705

Morley, J. E., \& Vellas, B. (2020). COVID-19 and older adult. The Journal of Nutrition, Health \& Aging, 24(4), 364-365.

Muhling, P., Bory, J., \& Haupt, H. (1984). Effect of air pollution on respiratory tract diseases in small children. Morbidity rate in residential areas with varying degrees of severe pollution. Fortschritte Der Medizin, 102, 831-834.

Otmani, A., Benchrif, A., Tahri, M., Bounakhla, M., Chakir, E.M., El Bouch, M., \& Krombi, M. (2020). Impactof Covid-19 lockdown on PM10, SO2 and NO2 concentrations in Salé City (Morocco). Science of the Total Environment, 735, 139541. https://doi.org/10.1016/j.scitotenv.2020.139541

Ouyang, W., Guo, B., Cai, G., Li, Q., Han, S., Liu, B., \& Liu, X. (2015). The washing effect of precipitation on particulate matter and the pollution dynamics of rainwater in downtown Beijing. Science of the Total Environment., 505, 306-314.

Paital, B., Das, K., \& Parida, S.K. (2020). Inter nation social lockdown versus medical care against COVID19, a mild environmental insight with special reference to India. Science of the Total Environment., 138914, PII S0048-96972032431-1.

Pentamwa, P., \& Oanh, N. T. K. (2008). Air quality in Southern Thailand during haze episode in relation to air mass trajectory. Songklanakarin Journal of Science and Technology, 30, 539-546.

Peter, H.S., Riad., Max Billib., Ahmed A. Hassan., Maha Abdel Salam., \& Mohamed Nour E Din. (2011). Application of the overlay weighted model and boolean logic to determine the best locations for artificial recharge of groundwater. Journal of Urban and Environmental Engineering. ISSN 1982-3932. https://doi.org/10.4090/juee.2011.v5n2.057066.

Prasanna, M. V., Chidambaram, S., \& Srinivasamoorthy, K. (2010). Statistical analysis of the hydrogeochemical evolution of groundwater in hard and sedimentary aquifers system of Gadilam river basin, South India. Journal of King Saud University (science)., 22(3), 133-145.

Reese, P. E., \& Marchette, N. J. (1991). Respiratory syncytial virus infection and prevalence of subgroup A and B in Hawaii. Journal of Clinical Microbiology, 29, 2614-2615.

Rhodes, C., \& Anderson, R. (2008). Contact rate calculation for a basic epidemic model. Mathematical Biosciences., 216, 56.

Şahin, M. (2020). Impact of weather on COVID-19 pandemic in Turkey. Science of the Total Environment, 728, 138810. https://doi.org/10.1016/j.scitotenv.2020.138810

Sani, S. (2006). The Environment: The Encyclopedia of Malaysia (pp. 91-98). Archipelago Press.

Schaffer, F. L., Soergel, M. E., \& Straube, D. C. (1976). Survival of airborne influenza virus: Effects of propagating host, relative humidity, and composition of spray fluids. Archives of Virology, 51, 263-273.

See, K. C., Liew, S. M., et al. (2020). COVID-19: four paediatric cases in Malaysia. International Journal of Infectious Diseases, 94, 125-127. https://doi.org/10.1016/j.ijid.2020.03.049

Senthil Kumar, G. R., \& Shankar, K. (2014). Assessment of groundwater potential zones using GIS. Frontiers in Geosciences, 2, 1-10.

Shaman, J., Kohn, M., \& Singer, B. H. (2009). Absolute humidity modulates influenza survival, transmission, and seasonality. Proceedings of the National Academy of Sciences of the United States of America, 106(9), 3243-3248. https://doi.org/10.1073/pnas.0806852106

Shankar, K., Gnanachandrasamy, G., Mahalakshmi, M., Devaraj, N., Prasanna, M.V., Chidambaram, S., \& Thilagavathi, R. (2021). Meteorological parameters and COVID-19 spread - Russia a case study. Environmental Resilience and Transformation in Times of COVID-19: Climate Change Effects on 
Environmental Functionality. Editors: AL. Ramanathan, S. Chidambaram, M.P. Jonathan, M.V. Prasanna, Pankaj Kumar and Francisco Munoz Arriola. Elsevier Publisher. ISBN: 978-0-32-385512-9

Shephard, R. J., \& Shek, P. N. (1998). Cold exposure and immune function. Canadian Journal of Physiology and Pharmacology, 76(9), 828-836. https://doi.org/10.1139/cjpp-76-9-828

Shi, P., Dong, Y., Yan, H., Li, X., Zhao, C., Liu, W., et al. (2020). The impact of temperature and absolute humidity on the Coronavirus Disease 2019 COVID-19 Outbreak-Evidence from China. medRxiv. https://doi.org/10.1101/2020.03.22.20038919

Silva, D. R., Viana, V. P., Muller, A. M., Livi, F. P., Paulo de Tarso, R., \& Dalcin. (2014). Respiratory viral infections and effects of meteorological parameters and air pollution in adults with respiratory symptoms admitted to the emergency room. Influenza and Other Respiratory Viruses., 81, 42-52.

Singhal, T. (2020). A review of Coronavirus Disease-2019 COVID-19. Indian Journal of Pediatrics, 87, 281-286. https://doi.org/10.1007/s12098-020-03263-6

Sohrabi, C., Alsafi, Z., O’Neill, N., Khan, M., Kerwan, A., Al-Jabir, A., et al. (2020). World Health Organization declares global emergency: A review of the 2019 novel coronavirus (COVID-19). International Journal of Surgery, 76, 71-76.

Steel, J., Palese, P., \& Lowen, A. C. (2011). Transmission of a 2009 pandemic influenza virus shows a sensitivity to temperature and humidity similar to that of an $\mathrm{H} 3 \mathrm{~N} 2$ seasonal strain. Journal of Virology, 85(3), 1400-1402. https://doi.org/10.1128/JVI.02186-10

Steyn, D. G., \& Castelli, S. T. (2010). Air pollution modeling and its application (pp. 4-5). Springer.

Tang, J. W. (2009). The effect of environmental parameters on the survival of airborne infectious agents. Journal of the Royal Society, Interface, 6, S737-S746.

Tellier, R. (2009). Aerosol transmission of influenza a virus: A review of new studies. Journal of the Royal Society, Interface, 6, https://doi.org/10.1098/rsif.2009.0302.focus

Tosepu, R., Gunawan, J., Effendy, D. S., Lestari, H., Bahar, H., \& Asfian, P. (2020). Correlation between weather and Covid-19 pandemic in Jakarta. Science of the Total Environment., 725, 1-4138436.

Tromp, S. W. (1980). Biometeorology-the impact of the weather and climate on humans and their environment animals and plants. In L. C. Thomas (Ed.), Heyden International Topics in Science (pp. 263318). Heyden \& Son Ltd.

Tromp, S., \& Hoffman, J. G. (1964). Medical bio- meteorology. Physics Today., 17, 53-54.

Wang, D., Hu, B., Hu, C., Zhu, F., Liu, X., Zhang, J., Wang, B., Xiang, H., Cheng, Z., \& Xiong, Y. (2020). Clinical characteristics of 138 hospitalized patients with 2019 novel coronavirus-infected pneumonia in Wuhan. China. JAMA.

Watson, M., Gilmour, R., Menzies, R., Ferson, M., \& Mclntyre, P. (2006). The association of respiratory viruses, temperature and other climatic parameters with the incidence of invasive pneumococcal disease in Sydney, Australia. Clinical Infectious Diseases., 42, 211-215.

Xie, J., \& Zhu, Y. (2020). Association between ambient temperature and COVID-19 infection in 122 cities from China. Science of the Total Environment, 724, 138201. https://doi.org/10.1016/j.scitotenv.2020. 138201

Xu, B., Fan, C., Wang, A., Zou, Y., Yu, Y., He, C., Xia, W., Zhang, J., \& Miao, Q. (2020). Suppressed T Cell-Mediated Immunity in Patients with COVID-19: A Clinical Retrospective Study in Wuhan, China. China 3/16/2020.

Xu, Z., Shi, L., Wang, Y., Zhang, J., Huang, L., Zhang, C., Liu, S., Zhao, P., Liu, H., Zhu, L., et al. (2020b). Pathological findings of COVID-19 associated with acute respiratory distress syndrome. The Lancet Respiratory Medicine, 8(4), 420-422.

Zhan Z, Zhao Y, Pang S, Zhong X, Wu C, Ding Z (2017) Temperature change between neighboring days and mortality in United States: a nationwide study. Science of the Total Environment, 584, 1152-1161.

Zhou, Z. X., \& Jiang, C. Q. (2004). Effect of environment and occupational hygiene factors of hospital infection on SARS outbreak. Zhonghua Lao Dong Wei Sheng Zhi Ye Bing Za Zhi, 22, 261-263.

Publisher's Note Springer Nature remains neutral with regard to jurisdictional claims in published maps and institutional affiliations. 


\section{Authors and Affiliations}

\section{Prasanna Mohan Viswanathan ${ }^{1}$ (D) Chidambaram Sabarathinam ${ }^{2}$ (D)} Shankar Karuppannan ${ }^{3}$ (D) Gnanachandrasamy Gopalakrishnan ${ }^{4,5}$ (D)

1 Department of Applied Geology, Faculty of Engineering and Science, Curtin University, Malaysia, CDT 250, 98009 Miri, Sarawak, Malaysia

2 Water Research Centre, Kuwait Institute for Scientific Research, P.O. Box 24885, 13109 Safat, Kuwait

3 Department of Applied Geology, School of Applied Natural Science, Adama Science and Technology University, Adama, Ethiopia

4 School of Geography and Planning, Sun Yat-Sen University, Guangzhou 510275, People's Republic of China

5 Center for Earth, Environment and Resources, Sun Yat-Sen University, Guangzhou 510275, People's Republic of China 